Review

\title{
The Physiology of Esophageal Reflexes
}

Ivan M. Lang *

Division of Gastroenterology and Hepatology, Department of Medicine, Medical College of Wisconsin, Milwaukee, USA; E-Mail: imlang@mcw.edu

* Correspondence: Ivan M. Lang; E-Mail: imlang@mcw.edu

Academic Editor: Massimo Arcerito

Special Issue: Gastroesophageal Reflux Disease: From Heartburn to Esophageal Adenocarcinoma

OBM Hepatology and Gastroenterology

2020, volume 4, issue 4

doi:10.21926/obm.hg.2004052
Received: August 17, 2020

Accepted: October 13, 2020

Published: November 02, 2020

\begin{abstract}
Several digestive tract reflexes involving the esophagus and its sphincter muscles have been identified, but to date, no comprehensive review has addressed most of these reflexes. The current review presents the known physiology of different esophageal reflexes in which either the esophagus or its sensory or motor portion of the reflex response is elaborated. The current review comprehensively examines the known and possible mechanisms underlying major esophageal reflexes, highlights the huge gaps in current knowledge and limitations of previous research, helps shed light on the physiology of these reflexes, and suggests how the knowledge gaps can be bridged. In conclusion, this review will be very useful for researchers, clinicians, and academicians around the world.
\end{abstract}

\section{Keywords}

Esophagus; physiology; reflexes; EPSR; EESR; GLIR; GERD; upper esophageal sphincter

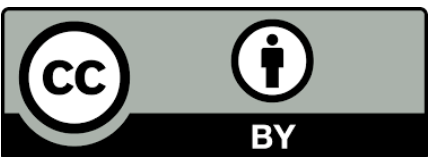

(C) 2020 by the author. This is an open access article distributed under the conditions of the Creative Commons by Attribution License, which permits unrestricted use, distribution, and reproduction in any medium or format, provided the original work is correctly cited. 


\section{Introduction}

This review presents the physiology of esophageal reflexes. Several characteristics of these reflexes-stimuli, responses, functions, and dysfunctions of the reflexes, receptor types and locations, afferent and efferent neural pathways, and the associated neural control mechanismsare also elaborated. Besides, the possible role of these reflexes in various clinical conditions has also been explored.

Herein, primary or secondary peristalsis, belching, and vomiting mechanisms of esophageal reflexes are not discussed as they have already been reviewed previously [1-5]. However, reflexes that activate peristalsis, belching, and swallowing in novel defined methods, which inhibit peristalsis, belching, and swallowing, and the subreflexes have been reviewed.

Many of these reflexes are significantly involved in various clinical conditions, such as gastroesophageal reflux disease (GERD). Thorough knowledge of the physiology of these reflexes is desirable for understanding several clinical conditions and initiate interventions.

\section{Upper Esophageal Sphincter Reflexes}

\subsection{Esophago-UES Contractile Reflex (EUCR) and Esophago-Esophageal Contractile Reflex (EECR)}

\subsubsection{Stimulus and Response}

The EUCR (Figure 1) and EECR (Figure 2) were first reported together in the same study [6], and have been investigated individually over the past 60 years. Both reflexes are presented together as they show many similarities, originate from the same upper esophageal sphincter (UES) muscles, and appear part of the same reflex response. These reflexes have been identified in both humans $[6-8]$ and animals $[9,10]$, but their mechanisms have been defined primarily in the decerebrate cat $[9,10]$.

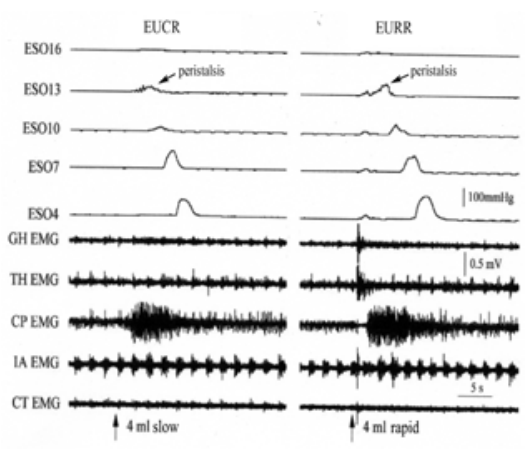

Figure 1 The esophago-UES contractile (EUCR) and relaxation (EURR) reflexes. This figure depicts the effects of 4-mL slow (EUCR) or 4-mL rapid distension (EURR) of the esophagus on the pharynx, larynx, and esophagus. Slow distension of the esophagus causes the reflex contraction of cricopharyngeus (CP), the primary muscle of the upper esophageal sphincter (UES). Rapid distension of the esophagus at the same location and the same volume inhibits the CP. ESO, esophageal; EMG, Electromyography showing the distance of muscles from lower esophageal sphincter (LES) shown on the left side of the figure; $\mathrm{GH}$, geniohyoideus; $\mathrm{TH}$, thyrohyoideus; $\mathrm{CP}$, cricopharyngeus; IA, interarytenoid; $\mathrm{CT}$, cricothyroideus. 


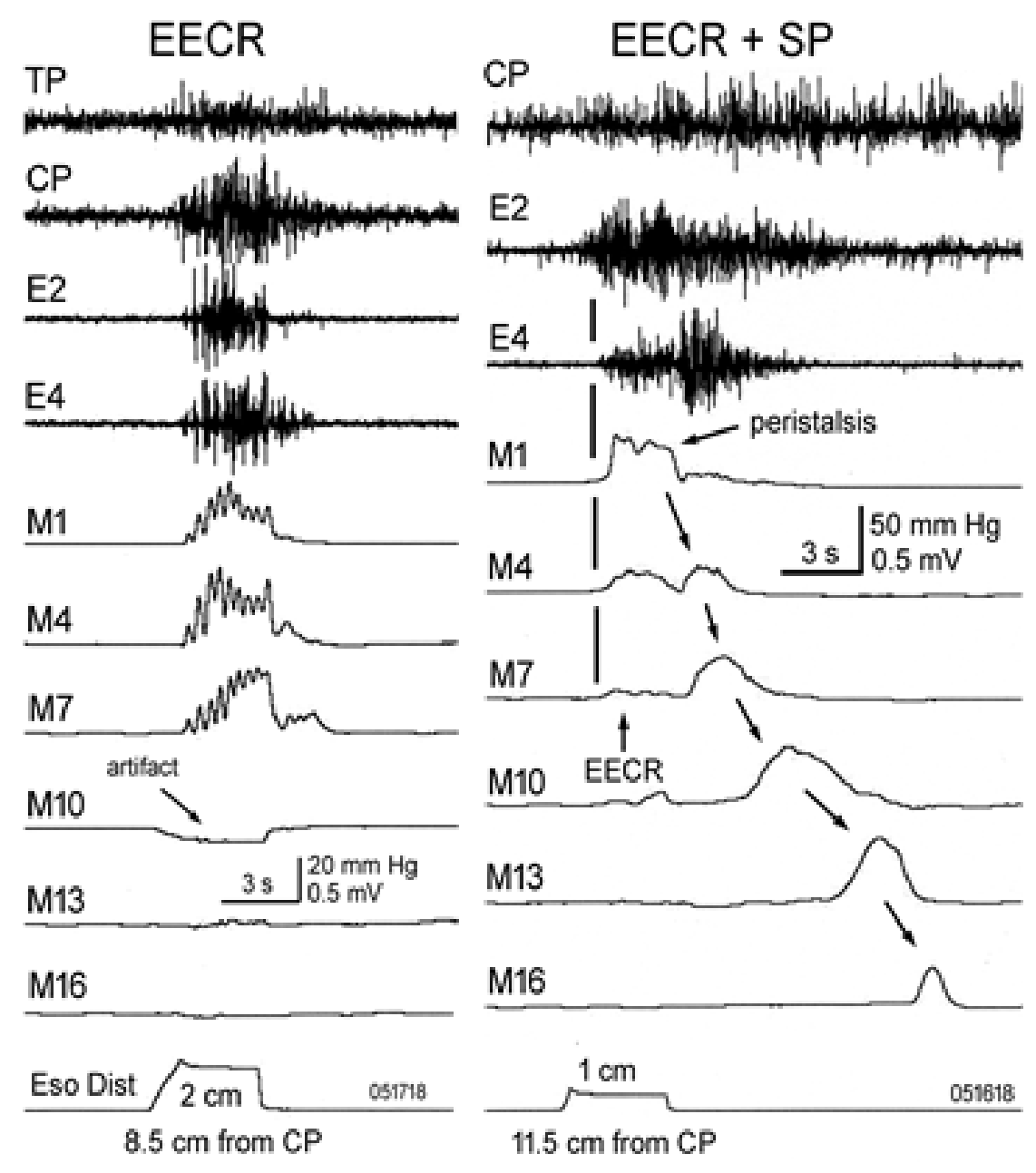

Figure 2 The esophago-esophageal contractile reflex (EECR). This figure shows that slow distension of the esophageal reflexes activates contraction or the stimulus of esophagus in the CP and TP in a decerebrate cat. The EECR is often followed by secondary peristalsis (SP) as shown in the right half of the illustration. TP, thyropharyngeus; $C P$, cricopharyngeus; E2, second esophageal EMG $2 \mathrm{~cm}$ from CP. M\#, manometry of the esophagus \# cm from the UES; ESO, esophageal; Dist, distension. \# shows the number of respective nerve/reflex; SP, secondary peristalsis.

Both EUCR and EECR occur simultaneously with the esophageal distension and can be activated from all areas of the esophagus; however, the magnitudes of these reflex responses are greater when activated from a striated muscle rather than from a smooth muscle portion of the esophagus [6-11].

The acute or chronic short term (less than $30 \mathrm{~min}$ ) exposure of the esophagus to hydrochloric acid $(\mathrm{HCl})$ demonstrated minimal effects on EUCR or EECR in decerebrate cats $[12,13]$, but both reflexes are significantly inhibited (Figure 3) by longer term acute (greater than $30 \mathrm{~min} \mathrm{HCL}$ exposure) or chronic exposures (15 $\mathrm{MI} \mathrm{HCl}$ exposure daily for four days) [10, 12-14] in humans and animals. 


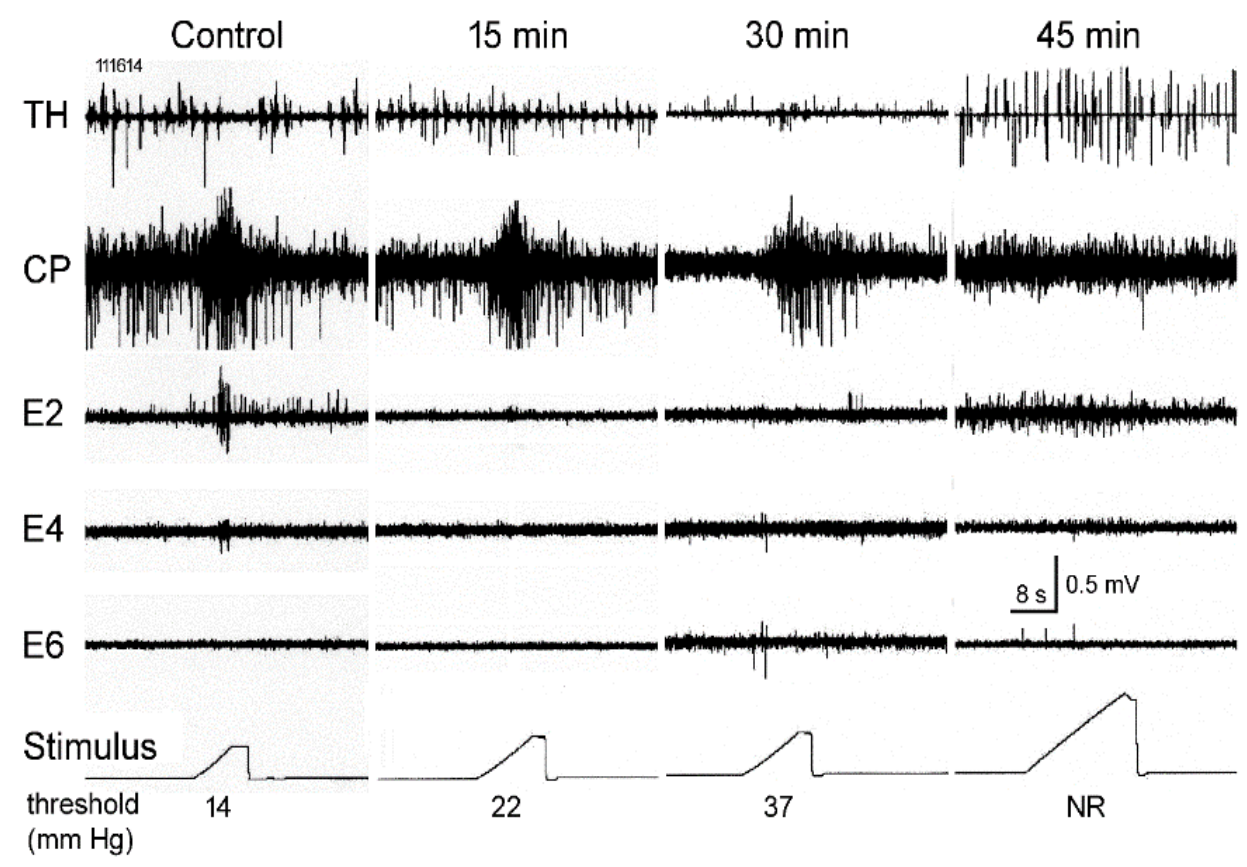

Figure 3 Effect of acute exposure of the esophagus to $\mathrm{HCl}$ on EUCR and EECR. In the control condition in decerebrate cats, distension of the esophagus at $8 \mathrm{~cm}$ from the $\mathrm{CP}$ activated the $C P$, i.e., EUCR, and esophagus above the stimulus, i.e., EECR, with 14 $\mathrm{mmHg}$ balloon pressure, but after $\mathrm{HCl}(0.1 \mathrm{~N})$ exposure, the balloon pressure needed to activate both EUCR and EECR was significantly elevated until the point of no response (NR) after 45 min of $\mathrm{HCl}$ exposure [13].

Shortly after acidic fluid infusion into the esophagus, spontaneous repetitive activation of the EUCR and EECR $[10,14]$ occurs in the striated muscle portion of the esophagus (Figure 4). This repetitive activation of the EUCR and EECR occurs more frequently when the acid is applied to the striated muscle portion of the esophagus [10]. This effect decreases with long term exposure of the esophagus to acid [10, 14]. We hereby hypothesize that this response is caused by sensitization and activation of highly sensitive mechanoreceptors. The repetitive nature of this response can be attributed to repetitive flushing of the cervical esophagus by activation of EUCR and EECR because simultaneous contraction of the cervical esophagus along with the closure of the UES moves luminal contents distally without activation of peristalsis. This repeated activation of EUCR and EECR may serve a significant anti-reflux function. The advantage of this protective response is that it does not require a UES opening that always occurs during swallowing [15] and is sometimes preceded by inspiration that occurs at the beginning of swallowing [16]. Inspiration with acid during swallowing in the cervical esophagus could lead to aspiration of acid. Therefore, it can be concluded that when acid is in the cervical esophagus, repetitive activation of EUCR and $E E C R$ is the most effective and safest way to remove this acid. 


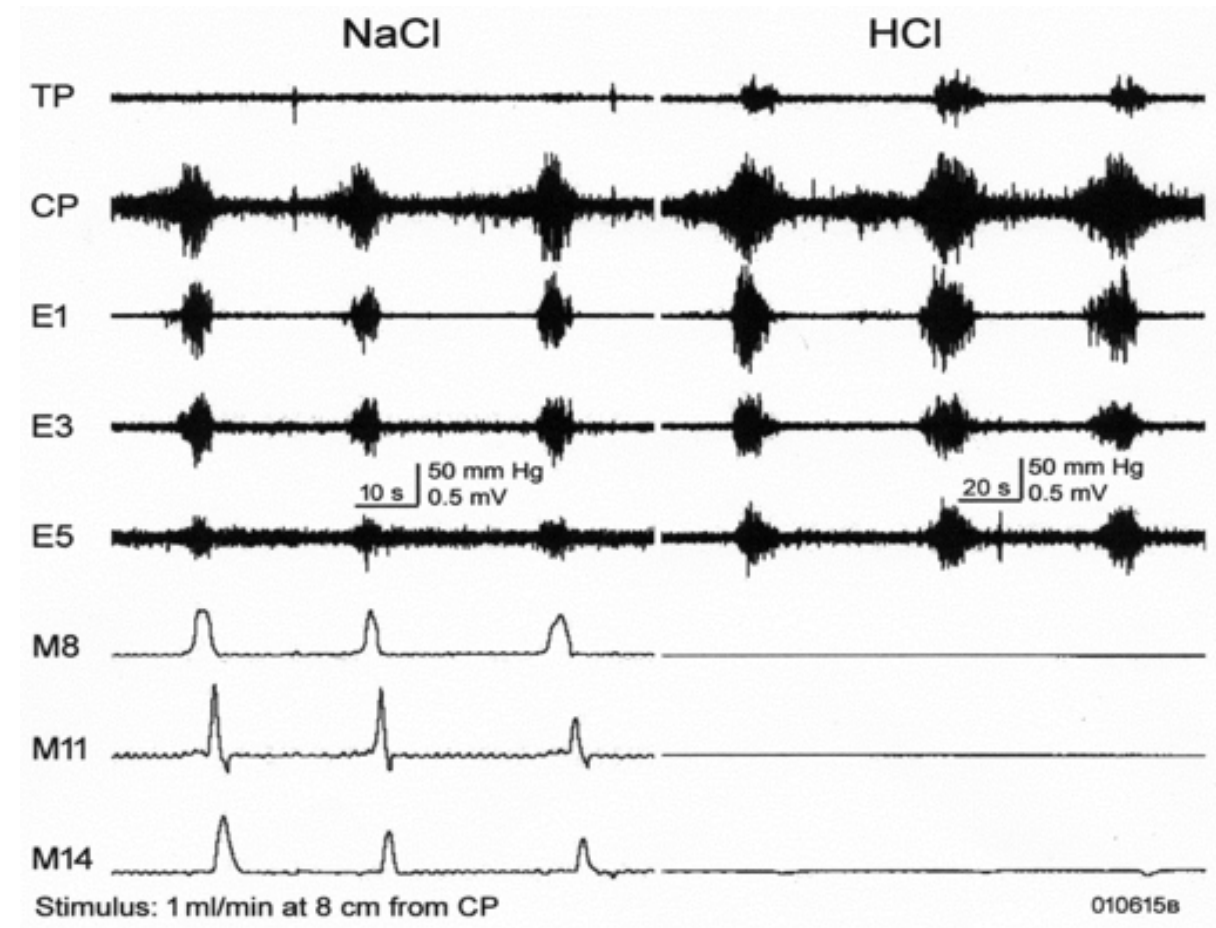

Figure 4 Effect of chemical stimulation of the esophagus on EECR and esophageal peristalsis. The infusion of $\mathrm{NaCl}$ repetitively activates esophageal peristalsis in the decerebrate cat that propagates the entire length of the esophagus. On the other hand, $\mathrm{HCl}$ infusion repetitively activates the EECR, which did not propagate. TP, thyropharyngeus; $\mathrm{CP}$, cricopharyngeus; E\#, EMG of the esophagus \# $\mathrm{cm}$ from the $\mathrm{CP}$;

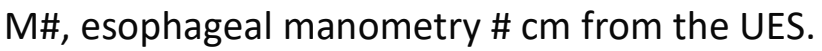

The EECR appears similar to esophageal peristalsis [10, 14] of the proximal esophagus, but these responses are very different because esophageal peristalsis propagates and the EECR does not, and the EECR involves activation of the TP whereas esophageal peristalsis does not (Figure 4). These responses appear similar because of the rapid propagation velocity of peristalsis in the proximal esophagus, making both responses to appear simultaneous. Although EECR was first identified and described in human studies [6], subsequent studies on EECR were inadequate. This lack of investigation may have led to some misconceptions in more recent human studies. It has been observed that an esophageal response that looks like peristalsis occasionally seems to stop before complete esophageal transit, indicating inhibition in the progression of this peristalsis [14]. However, it is more likely that this response was EECR, not esophageal peristalsis, as there was no propagation or inhibition. Further studies are suggested to unravel the mechanism of the EECR, especially on humans, to arrive at conclusive evidence.

A new reflex associated with EECR has recently been described [10]. When the EECR of the smooth muscle from the esophagus is activated, it inhibits activation of the striated muscle EECR through a neural pathway involving both the ENS and CNS (Figure 5). It is hypothesized that this inhibitory response from the smooth muscle in the esophagus is important during small gastroesophageal reflux (GER) events. Under these conditions, the EECR of the striated muscle of the esophagus is not necessitated as this bolus can be better removed by esophageal peristalsis. 
A

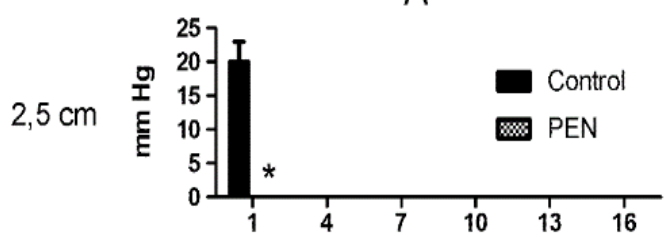

$5.5 \mathrm{~cm}$

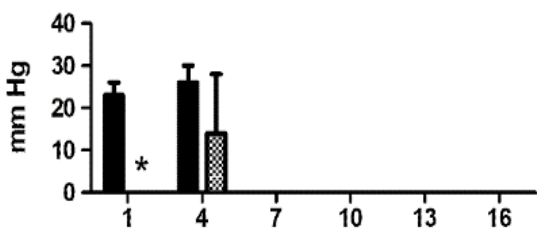

$8.5 \mathrm{~cm}$

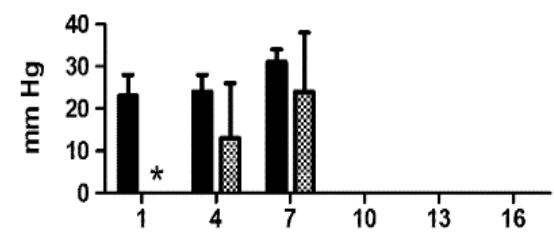

$11.5 \mathrm{~cm}$
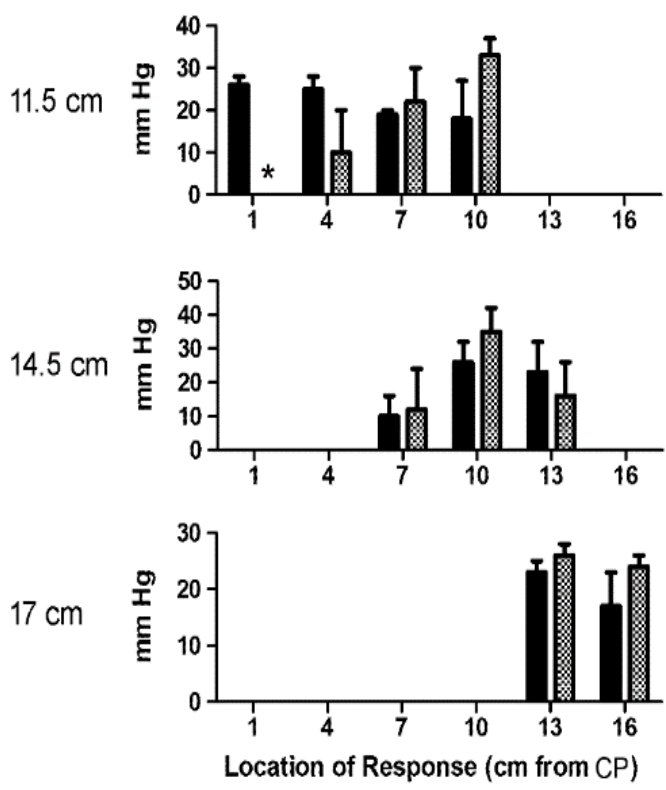

B
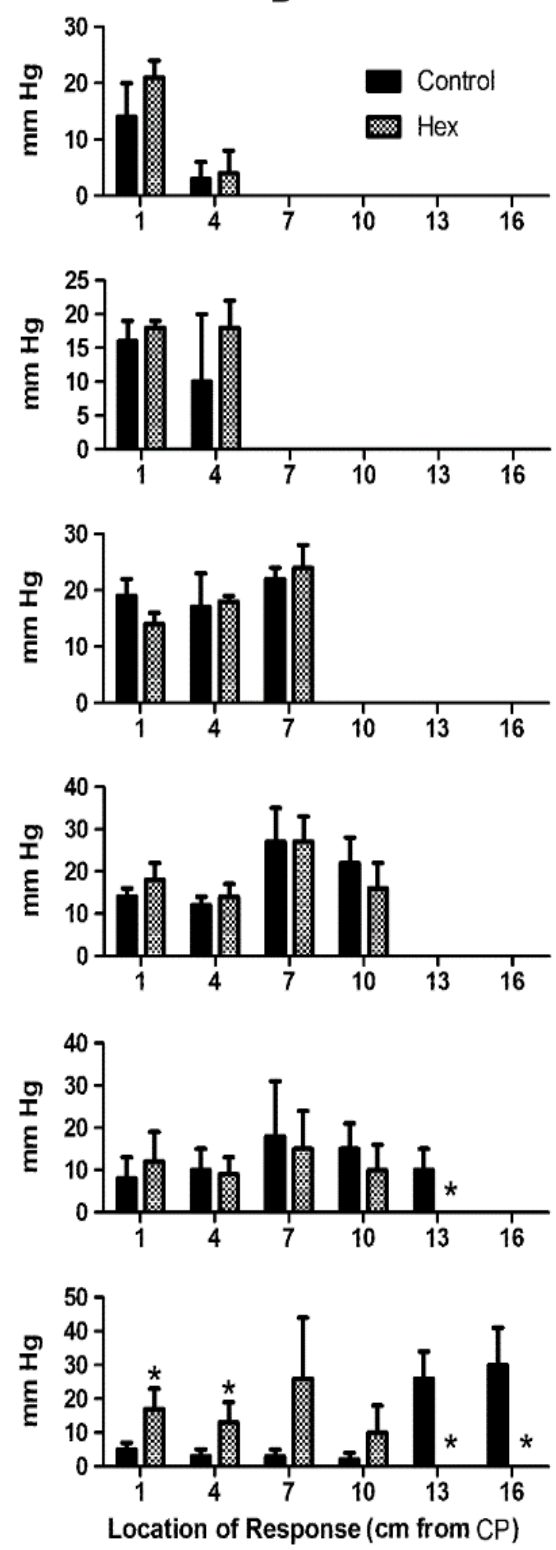

Figure 5 The effect of Hexamethonium (Hex) on EECR in the decerebrate cat. Graphs under B show that Hex administration increased the magnitude of the EECR of the striated muscle esophagus activated by distension of the smooth muscle esophagus, indicating that an inhibitory reflex mediated by ganglionic transmission from the smooth muscle esophagus was blocked. Hex exposure also blocked the EECR of the smooth muscle esophagus activated by its distension, indicating that the EECR of smooth muscle esophagus is mediated by the ENS. The numbers on the left side of the graphs indicate the distance of the stimulating balloon from the CP. The distal onethird of the cat esophagus is the smooth muscle. Graph A lists the effects of transecting the pharyngo-esophageal nerve (PEN) on EECR. The PEN is a branch of the vagus nerve, which innervates the proximal esophagus and UES in animals. The location of the responses after control and Hex administration are shown separately under part A \& B. 


\subsubsection{Function}

The EUCR closes the UES $[6,7,11,12,14]$, and the EECR strongly contracts the upper part of the esophagus just below the UES in response to distension of the esophagus. It suggests that both the EUCR and EECR may prevent esophago-pharyngeal reflux (EPR).

The EUCR and EECR display some striking similarities in functions in respect of secondary peristalsis. Types of stimuli that activate EUCR and EECR also activate secondary peristalsis. However, there must be certain situations in which EUCR/EECR is preferred over the secondary peristalsis, and mechanisms to make this distinction happen must be present. While EUCR/EECR and secondary peristalsis are activated by slow mechanical stimulation of the esophagus, different receptors mediate each response. The EUCR and EECR are activated by stimulation of slowlyadapting muscular tension receptors while secondary peristalsis is activated by stimulation of the tension/mucosal (T/M) receptors [9, 10]. The muscular tension receptors are less sensitive than the $T / M$ receptors. Hence, EUCR and EECR require greater esophageal stimuli for activating esophageal peristalsis. Another possible difference between activation of EUCR/EECR and esophageal peristalsis is the rapidity and consistency of the response. The EUCR and EECR are activated in a one-to-one fashion with the response at a very short time delay from the stimulus [9, 10]. On the other hand, esophageal peristalsis is activated in a probabilistic [6] manner so that the time delay from stimulus to response is more variable and slower than the delays during activation of the EUCR and EECR.

Another important issue regarding the function of EUCR and EECR compared to esophageal peristalsis, especially in humans, is the difference between smooth and striated muscle esophagus. In humans, distending stimuli of the striated muscle portion of the esophagus at $6 \mathrm{~cm}$ from the UES and above do not elicit esophageal peristalsis [7]. On the other hand, strong balloon distension of the smooth muscle esophagus activates EUCR and EECR above the stimulus and esophageal peristalsis below the stimulus, when the distension is released $[17,18]$. More fluid infusion into the smooth muscle esophagus regularly activates esophageal peristalsis, but in a probabilistic manner [6]. Therefore, it may be concluded that in situations requiring an immediate and definite response to prevent EPR, the EUCR and EECR are activated rather than esophageal peristalsis.

\subsubsection{Receptors}

Mechanoreceptors of the esophagus are found in the mucosal [19-24], muscular [21, 23-27], and serosal [23] layers. Earlier studies have found that intraluminal lidocaine administration or surgical removal of the mucosa and submucosa blocked some esophageal reflexes, but not the EUCR [9]. Therefore, the mechanoreceptors mediating the EUCR lie probably in the muscular layer of the esophagus, and the only identified mechanoreceptors of the muscular layer of the esophagus are the slowly adapting tension receptors [21, 23-28]. This conclusion is also supported by the observation that the EUCR response is directly related to the stimulus in time and magnitude $[6,9]$, which are characteristics of vagal afferent responses to stimulation of esophageal slowly adapting tension receptors [21, 23-28]. The receptors mediating the EECR have not been investigated yet, but it appears that they may resemble the receptors mediating the EUCR. 


\subsubsection{Innervation}

The motor and sensory innervation of the EUCR and EECR are evaluated separately because the motor innervation of the UES differs between humans [29] and animals [30-32], and has different quantities of smooth and striated muscles in the esophagus. Regardless of these differences, both are vago-vagal reflexes.

2.1.4.1 EUCR. The thoracic vagus nerve is the afferent nerve of the EUCR generated from the thoracic esophagus $[9,10,33,34]$. The afferent nerve of the EUCR generated from the proximal thoracic, and distal cervical esophagus is the caudally-directed recurrent laryngeal nerve (RLN), a branch of the thoracic vagus nerve $[33,35,36]$. The afferent innervation of the EUCR generated from the cervical esophagus is the cervical branch of the $\operatorname{RLN}[33,37]$, which joins the superior laryngeal nerve [SLN], vagus nerve, and nodose ganglion neurons [29, 37]. This afferent innervation of the EUCR is corroborated by physiological studies that found that transection of the SLN blocked the EUCR generated from the cervical esophagus, and transection of the caudally directed RLN blocked the EUCR generated from the proximal thoracic esophagus [33].

The efferent innervation of the EUCR, i.e., the motor nerve of the UES, differs between humans and animals. In humans, the efferents of the EUCR are probably located in the cervical branch of the RLN [38-40]; however, there is no conclusive study defining the motor innervation of the UES in humans. Transection of the pharyngo-esophageal nerve (PEN) in animals reportedly blocks the EUCR activation from all regions of the esophagus [10]. Therefore, the efferents of the EUCR are in the PEN, a motor nerve of the UES [41, 42], and a branch of the vagus nerve [41].

2.1.4.2 EECR. The afferents of the EECR in animals [10], and probably also in humans, are the same as the afferents of the EUCR, as mentioned. The efferent innervation of the EECR of the cervical esophagus, like the EUCR, is the motor nerve of that portion of the esophagus, which is the PEN in animals [10] and RLN [38-40] in humans. The efferent innervation of the remainder of the EECR in both humans and animals is the motor innervation of the remainder of the esophagus $[29,30]$, which is the RLN and vagus nerve.

\subsubsection{Neural Control Mechanisms}

As both EUCR and EECR are mediated by afferents and efferents of the vagus nerves [9, 10], these reflexes must be mediated by the CNS. The EUCR can be activated in a decerebrate animal [9]; therefore, suprabulbar nuclei are not directly involved in the control of these reflexes. Previous studies [43] have established that stimulation of the EUCR activates several medullary nuclei (as shown in Figure 6): central, dorsolateral, and ventrolateral subnuclei of the nucleus tractus solitarius (NTS), the central and rostral subnuclei of the dorsal motor nucleus (DMN), and the rostral subnucleus of the nucleus ambiguus (NA). Considering the similarity in the innervation and function of the EECR with the EUCR, it is likely that the EECR is mediated by the same brain stem nuclei as the EUCR.

There is one significant difference in the neural control mechanism between EUCR and EECR. The afferents of the EECR from the smooth, not the striated muscle portion of the esophagus, synapse in the enteric nervous system (ENS) before projecting to the brain stem through the vagus nerves [10]. 


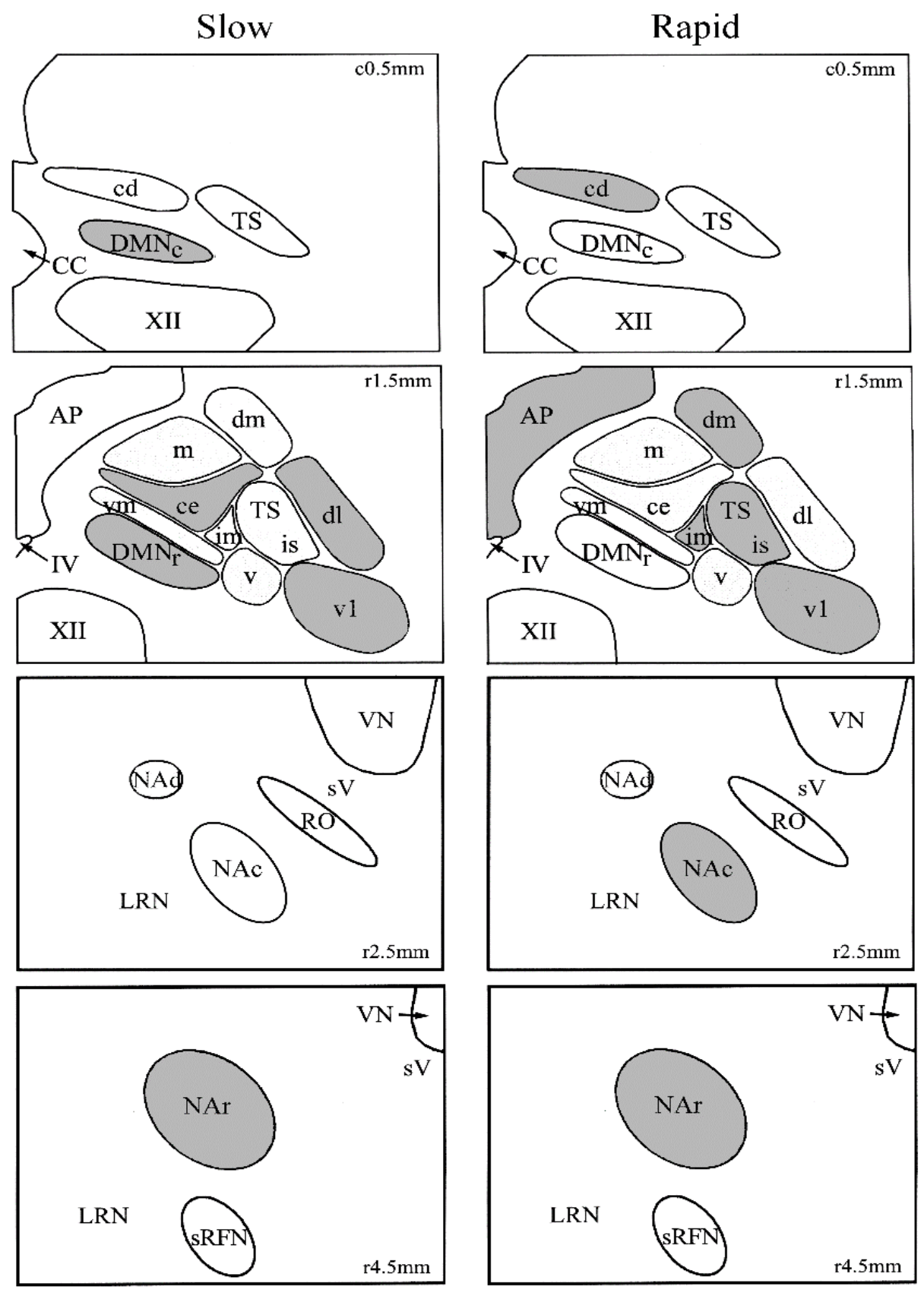

Figure 6 Effects of slow or rapid distension of esophagus on activation of brainstem nuclei. Stimulation of EUCR/EECR by slow distension or EURR by rapid distension activated the shaded nuclei in these brain slice images [43]. DMN, dorsal motor nucleus; AP, area postrema; XII, hypoglossal nucleus; NA, nucleus ambiguus; VN, trigeminal nucleus; IV, fourth ventricle; RFN, retro facial nucleus; LRN, lateral reticular nucleus; TS, tractus solitarius; NTS nucleus tractus solitarius subnuclei: $M$, medial; dm, dorsomedial; ce, central; dl, dorsolateral; v, ventral; vl, ventrolateral; vm, ventromedial; $v$, ventral; is, interstitial; im, intermediate.

\subsubsection{Dysfunction}

Acute low dose acid exposure of the esophagus in normal humans causes increased sensitization to activate the EUCR [44], but patients with supra-esophageal reflux disease (SERD) 
show decreased sensitization to activate EUCR [14]. These results testify that while short term esophageal acid exposure sensitizes EUCR, thereby increasing protection against SER; this protective effect may be diminished with longer-term esophageal acid exposure leading to SERD. Animal studies have confirmed that acute high doses or repeated chronic exposure of the esophagus to acid desensitize it for activation of the EUCR [13]. Therefore, this differential effect of esophageal acid exposure on EUCR concludes that GERD or SERD can occur independently of the other condition.

Acute esophageal acid exposure of the esophagus in animals has not been shown to increase the sensitization of EUCR [13], and in humans has not been found to decrease the sensitization of EUCR [44]. These failures in both cases may be due to dose effects. In humans, the dose may have been too low to inhibit the EUCR, and in animals may have been disproportionately high to sensitize the EUCR. This was suggested by experimental studies [44], since the excitatory effect of acid exposure on the EUCR was very small in humans, and the dose used in animals [13] was larger than that used in humans [44].

The role of EECR in GERD or SERD has not been much investigated; however, both GERD \& SERD seem to be triggered by EECR like reflexes as these reflexes are probably part of the same reflex response. Also, the inhibition of the striated muscle EECR by the smooth muscle EECR may play a role in reflux diseases. If GER causes inhibition of the smooth muscle EECR, it may also decrease the inhibition of the striated muscle EECR. Therefore, under these conditions, the function of the striated muscle EECR is sensitized to assist in preventing reflux into the striated muscle esophagus and SER.

\subsection{EURR: Esophago-UES Relaxation Reflex}

\subsubsection{Stimulus and Response}

Previous studies have shown that rapid injection of air into the esophagus causes relaxation of the UES in humans [45-48]. Animal studies [9] have found that rapid injection of small amounts of air directed locally at right angles to the esophageal mucosa at any level of the esophagus (Figure 1) inhibit EMG activity of the cricopharyngeus muscle, the main muscle of the UES [49]. The EURR has been found to be an important subreflex of belching [4].

In contrast to the EUCR and EECR, esophageal acid exposure significantly sensitizes the mechanoreceptors to activation of EURR before the acid desensitizes the receptors [13]. This sensitization was observed acutely and chronically (Figure 7). Besides, chronic exposure of the esophagus to acid increased the incidence of spontaneous activation of the EURR (Figure 8), which may have a role in GER as mentioned here below. 

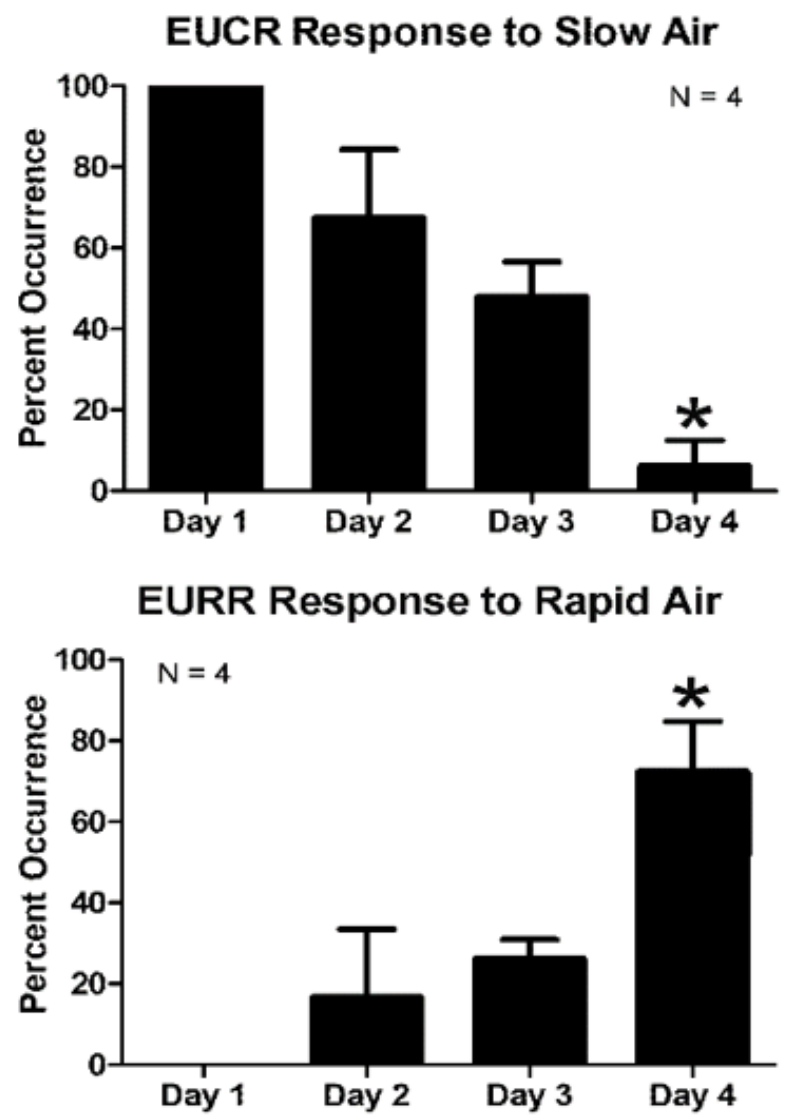

Figure 7 Comparison of the effects of chronic acid exposure of the esophagus on EUCR and EURR to slow and rapid air. Chronic daily 15-min exposure of the esophagus to 0.1 $\mathrm{N} \mathrm{HCl}$ inhibits activation of the EUCR but sensitizes the activation of EURR. The figure shows that on day 4, EUCR response to slow air is poor but EURR response to rapid air is very high.

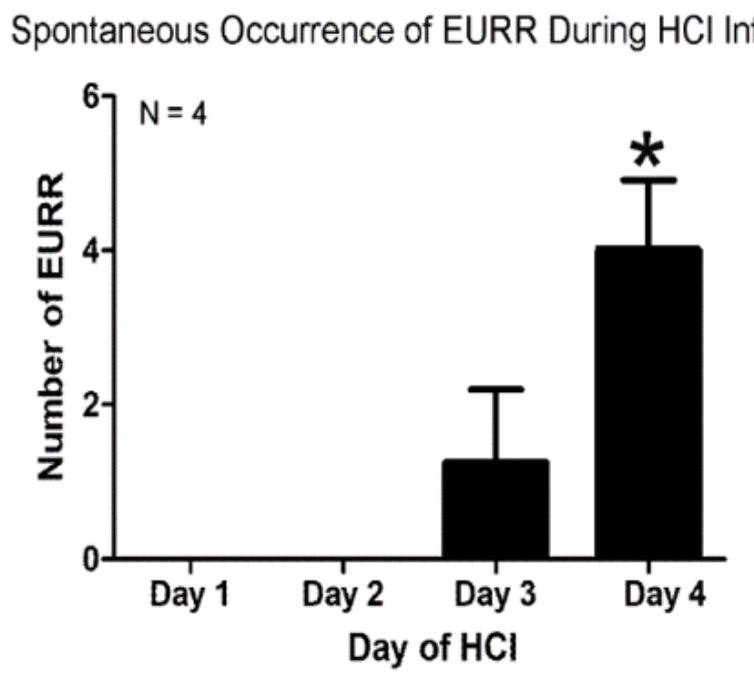

Figure 8 Effect of chronic exposure of the esophagus to $\mathrm{HCl}$ on the spontaneous occurrence of the EURR. After four days of 15-min daily HCL exposure in chronically instrumented cats, the incidence of spontaneous occurrence of the EURR showed a significant increase. 


\subsubsection{Function}

EURR (Figure 4) opens the UES to allow air from the stomach to be expelled through the esophagus (Figure 1). The EURR is the primary subreflex $[50,51]$ of the belch response (Figure 9).

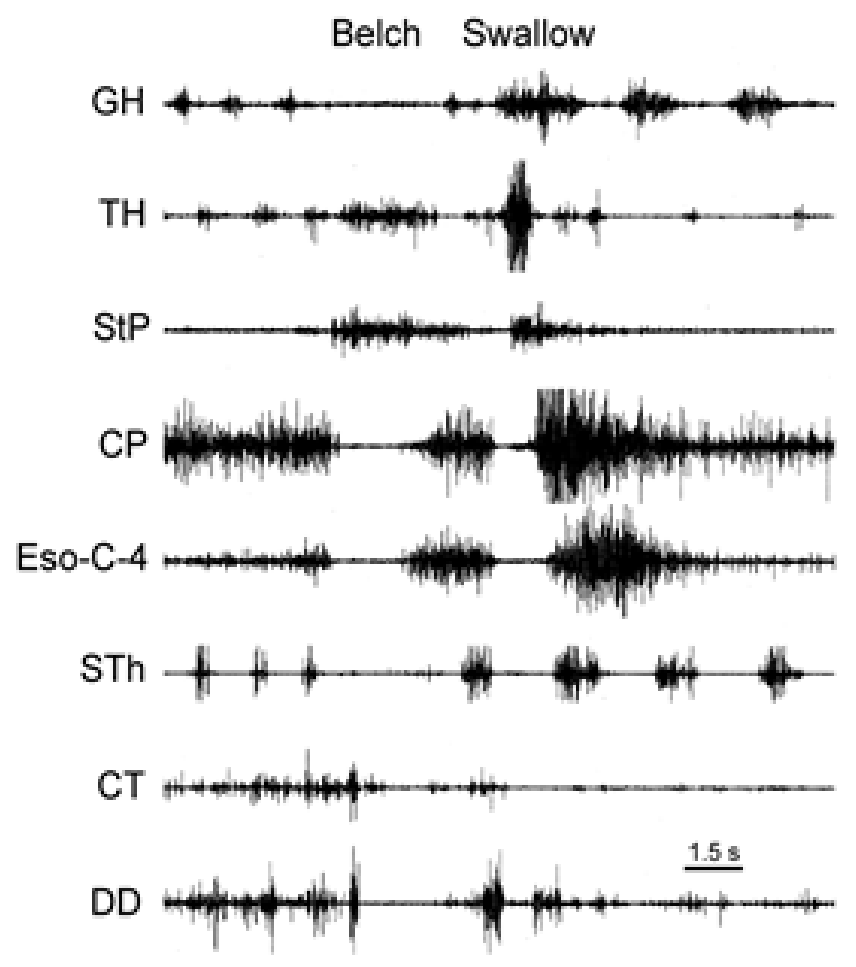

Figure 9 EURR during belch and swallowing. This figure depicts the responses of eight muscles during a spontaneous belch in a chronically instrumented dog. The belch is associated with simultaneous activation of thyrohyoideus (TH), stylopharyngeus (StP) muscles; and with the relaxation of the CP, Eso-C-4, and sternothyroideus (STh) muscles. These actions probably elevate the larynx and open the UES. GH, geniohyoideus; $\mathrm{CP}$, cricopharyngeus; Eso-C-4; cervical esophagus $4 \mathrm{~cm}$ from the $\mathrm{CP} ; \mathrm{CT}$, cricothyroideus; DD, diaphragmatic dome.

EURR can occur without activation of a full belch response $[9,52]$ and may also function to allow EPR. One such reflex response is the supragastric belch (SGB) response [Figure 10], which occurs in some GERD patients. SGB indicates a situation in which "air rapidly enters the esophagus from above followed by rapid expulsion of the air before it has reached the stomach" [53]. Initially, it was thought that this was a voluntary response [53-55], but recent studies [49] suggest that this may be a learned reflex response. It was observed in studies on decerebrate cats that rapid distention of the esophagus with a balloon could trigger an inhalation response that is immediately followed by activation of the EURR and release of air out of the esophagus and mouth [56]. The thoracic esophagus showed greater sensitivity to this reflex response than the cervical esophagus, and this response was sensitized by the exposure of the esophagus to acids [56]. All subreflexes of the SGB were blocked by vagotomy [56]. Local anesthesia of the esophageal mucosa blocked EURR, but could not trigger reflex activation of inhalation [56]. It is hypothesized that patients with a large number of GER that activate SGB over time learn to 
voluntarily initiate the SGB by rapid inhalation. Overall, belching can be learned [55], and swallowing is a digestive tract reflex response [54-56] that is activated voluntarily [57].

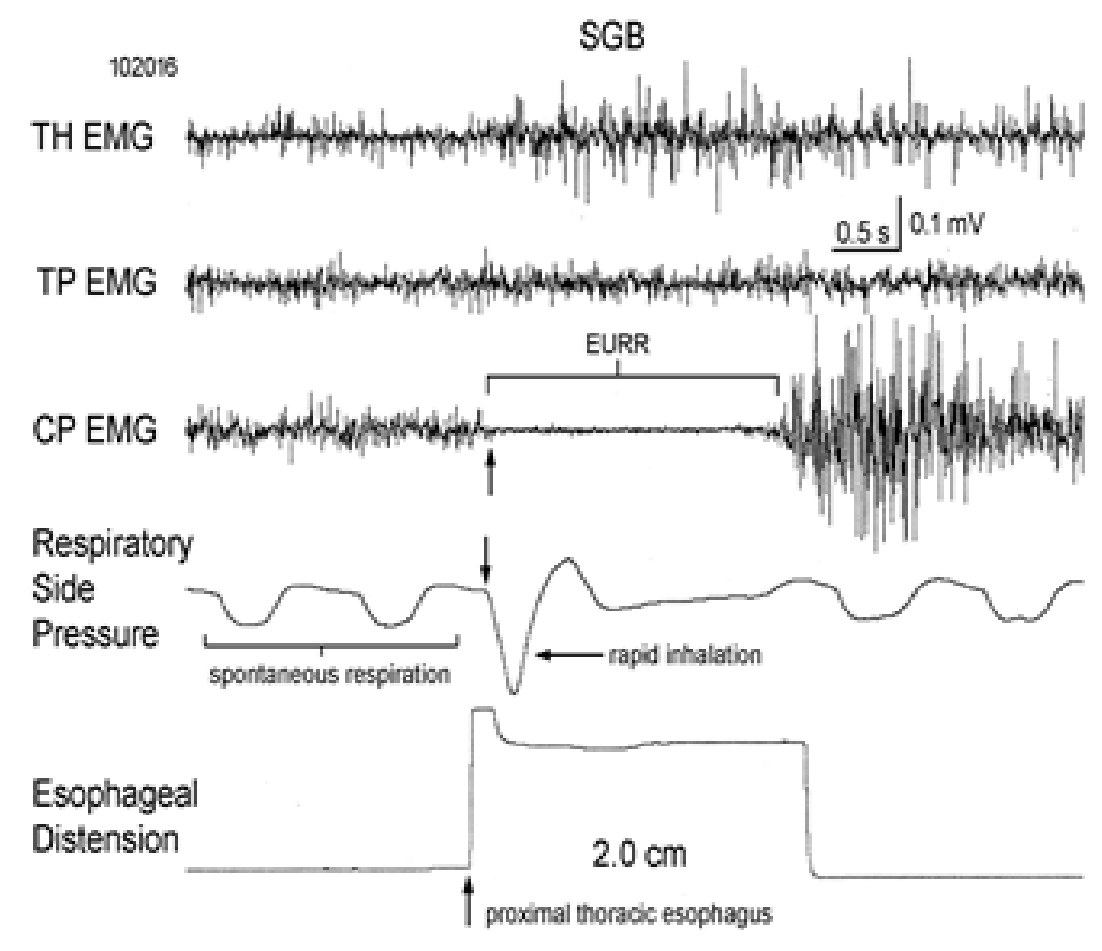

Figure 10 Supragastric belch (SGB) showing spontaneous respiration and inhalation, esophageal distension, and EMG reflexes of three muscles: TH, TP, and CP. Rapid distension of the esophagus in a decerebrate cat activated both the EURR and rapid inhalation similar to the SGB. This figure demonstrates that the SGB can be activated by esophageal reflexes. TH, thyrohyoideus; TP, thyropharyngeus; $\mathrm{CP}$, cricopharyngeus.

\subsubsection{Receptors}

Several studies have documented that mucosal application of local anesthesia or surgical removal of the mucosal/submucosal layer of the esophagus blocks EURR, and not EUCR [9], suggesting the presence of EURR, which is the mediating receptors in the mucosa or submucosa of the esophagus. The esophageal mucosa contains rapidly-adapting tension receptors [20-24], which exhibit characteristics to trigger EURR. These receptors are activated by rapid tension of the esophageal mucosa, and the responses are maximum at the very beginning and the end stage of the stimulus, not in the middle of the stimulus. Therefore, it is highly likely that the rapidlyadapting mucosal receptors of the esophagus mediate the EURR.

\subsubsection{Innervation}

The EURR is blocked by cervical vagotomy in animals [6]. Pharyngoesophageal nerve (PEN) is the efferent nerve of the UES in animals $[41,42,58]$, and the vagus nerve is the afferent nerve involved in EURR. Since the recurrent laryngeal nerve (RLN), also known as the inferior laryngeal nerve (ILN) and a branch of the cervical vagus nerve, mediates efferent innervation of the UES in humans [38-40], the afferents and efferents mediating the EURR in humans are located in the 
vagus nerve. As described previously, the cervical esophageal afferents reside in the cervical RLN, which feeds into the SLN and the vagus nerve. The afferent pathway for the EURR activated from the thoracic esophagus is also through this route as SLN transection blocks the EURR [33].

\subsubsection{Neural Control Mechanism}

The brain stem nuclei in decerebrate cats mediating the EURR were identified by measuring $c$ fos protein activation after repeated stimulation of the EURR [43]. One study revealed (Figure 6) that the EURR is mediated by the cranial dorsal, intermediate, interstitial, dorsomedial, and ventrolateral subnuclei of the NT; caudal and rostral subnuclei of the NA; ventrolateral subnucleus of the DMN; and the area postrema (AP). While suprabulbar nuclei may alter the EURR, the basic reflex is mediated by these brain stem nuclei because the EURR is not significantly altered after decerebration [9].

The AP is one of the strongest nuclei, activated during the belching [43] mechanism, and is also significantly activated during vomiting [59]. Both vomiting and belching are digestive tract reflux functions; therefore, the AP may have unique and similar roles in the reflux function for vomiting and belching. Although lesions of the AP block emesis [60, 61], studies have found that the Botzinger nucleus contains nuclei controlling the motor events of emesis [62,63]. Therefore, the AP may not be the motor nucleus for emesis and belching. Some studies have shown that stimulation of the AP inhibits the digestive tract function [64, 65]. So, in this review, it is hypothesized that the AP plays a role to inhibit the normal orthograde and anti-reflux reflexes that counter the reflux functions of vomiting and belching. Further studies are needed to confirm this hypothesis.

\subsubsection{Dysfunction}

Considering that the EURR removes the esophago-pharyngeal barrier to reflux, it is possible that increasing the sensitization of the EURR could lead to EPR. Several studies [13] have shown that short-term acid exposure of the esophagus enhances the sensitivity to activate the EURR. Clinical studies [14] have found that the EURR in SERD patients gets sensitized. Therefore, gastroesophageal acid reflux (GERD) may trigger EPR by sensitizing the esophagus to activate the EURR. Besides, the EURR is desensitized with longer-term esophageal acid exposure in animals [13]. The patients with SERD display decreased sensitivity to activation of the EURR [14]. Further studies are suggested to evaluate the role of EURR in SERD.

\subsection{Pharyngo-UES Contractile Reflex (PUCR)}

\subsubsection{Stimulus and Response}

Rapid stimulation of the pharynx in humans with small amounts of fluids causes a significant increase in UES tone $[66,67]$. Similarly, in decerebrate cats, touch or pressure on the pharyngeal mucosa of the naso-, laryngo-, or hypopharynx increases EMG activity of the cricopharyngeus muscle [68]. The hypopharynx is the most sensitive portion of the pharynx for activating PUCR as shown in Figure 11. 


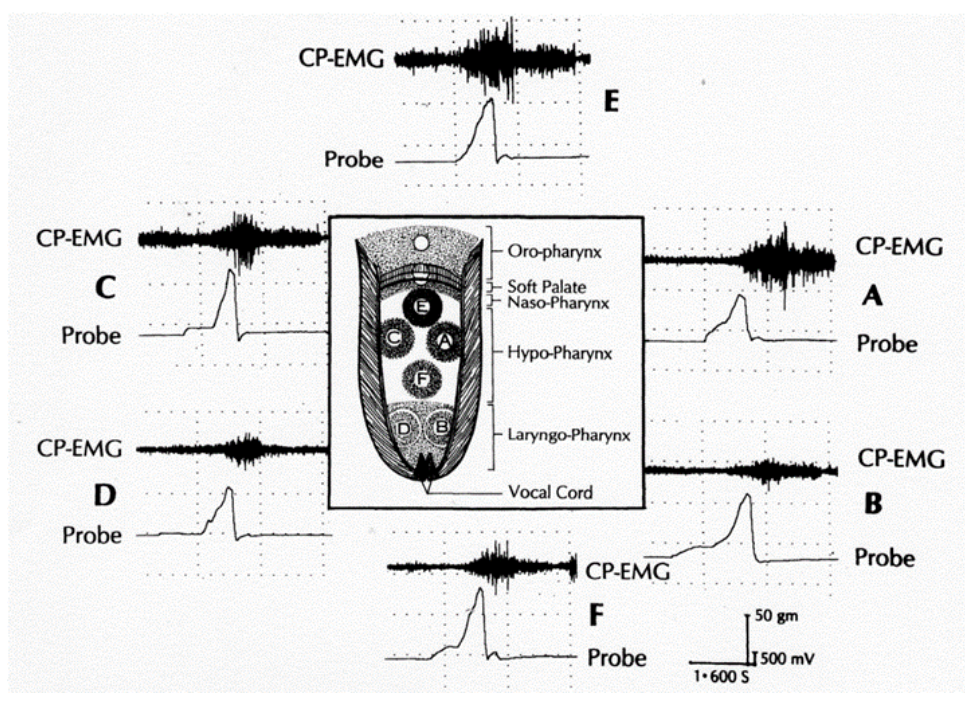

Figure 11 The pharyngo-UES contractile reflex (PUCR). This figure shows that mild tension of the pharyngeal mucosa at different locations indicated reflex activation of the $\mathrm{CP}$ in a decerebrate cat. Tension in all areas of the pharynx activated the $\mathrm{CP}$, but naso-and hypo-pharynx were the most sensitive. CP-EMG, electromyographical recording of the cricopharyngeus muscle.

\subsubsection{Function}

There is no known function of the PUCR, but it has been theorized that the PUCR plays a role in preventing further SER after an initial SER episode $[66,67]$. Further studies are required to validate this hypothesis.

\subsubsection{Receptors}

It remains poorly understood which specific receptors mediate the PUCR. PUCR can be activated by a slight touch of the pharyngeal mucosa and can be blocked by applying local anesthesia on the pharyngeal mucosa; therefore, it is likely that the receptors enabling PUCR are mucosal tension receptors of the pharynx [68].

\subsubsection{Innervation}

The PUCR was blocked by cutting the glossopharyngeal nerve (GPN) or PEN in decerebrate cats [68]. Since the PEN is the motor nerve of the UES in animals [41, 42], the GPN may be the sensory nerve for this reflex. The motor nerve of the PUCR is the motor nerve of the UES (called PEN in animals [41, 42] and RLN in humans [38-40]).

\subsubsection{Neural Control Mechanism}

Since PUCR is mediated by the vagus nerve [38-42], it could be controlled by CNS nuclei. Further, as PUCR is not blocked by decerebration [68], it might be controlled by brain stem nuclei. However, the nuclei controlling the PUCR remain unexplored as the CNS control of the PUCR has not been studied. 


\subsubsection{Dysfunction}

The effects of PUCR dysfunction are poorly understood, but the PUCR is inhibited in posterior laryngitis patients [44]. It is hypothesized that this inhibition of PUCR is due to alteration in the GPN, the sensory nerve for the PUCR [68]. However, the functional deficit caused by this inhibition needs to be further studied due to poor knowledge about them.

\section{Esophageal Reflexes}

\subsection{EPSR: Esophagus Activated Pharyngeal Swallow Response}

\subsubsection{Stimulus and Response}

The EPSR is the activation of the pharyngeal phase of swallowing due to stimulation of the esophagus (Figure 12) that readily occurs in infant humans [69, 70] and animals [56], but not in adult humans $[7,71]$. The EPSR occurs in a probabilistic manner similar to secondary peristalsis. There is no one-to-one stimulus to response relationship of EPSR as with most other esophageal reflexes [9]. The EPSR is triggered by chance depending on the amount of distension, length of the distension in the esophagus, and the location of the stimulus in the esophagus [56]. The EPSR occurs in cats with an optimum increase when the esophagus is distended $80 \%$ above basal diameter. The larger the length of the stimulus the better it is for the reflex and the optimum location of EPSR is, when the stimulus is closest to the UES [56]. The stimulus can be either a slow square wave or ramp style distension (Figure 12). The EPSR can also be activated by acid stimulation of the esophagus, particularly in the thoracic esophagus (Figure 13 [56]).

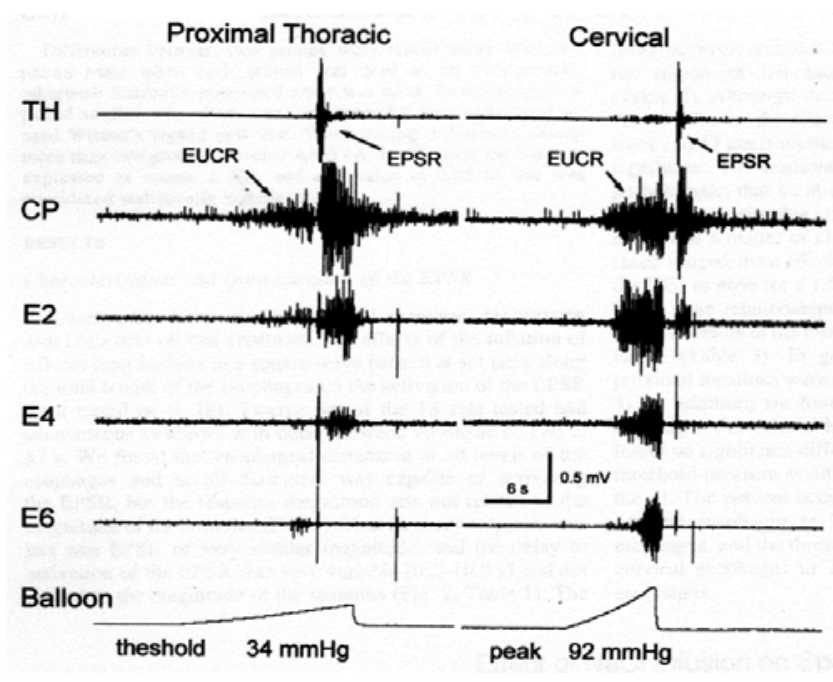

Figure 12 Mechanism of the esophagus-stimulated swallow response (EPSR). This figure shows that slow or rapid distension of the cervical or proximal thoracic esophagus in a decerebrate cat activates EUCR followed by the pharyngeal swallow (EPSR). While the EUCR occurs at some delay after attaining threshold pressure, the EPSR occurs randomly. During slow distension, the EPSR occurred during the stimulus, but with rapid stimulation, it occurred immediately after removal of the stimulus. On the right in the above figure, nerves in EPSR are depicted. TH, thyrohyoideus; CP, cricopharyngeus; E\#, esophagus \# cm from the CP. 


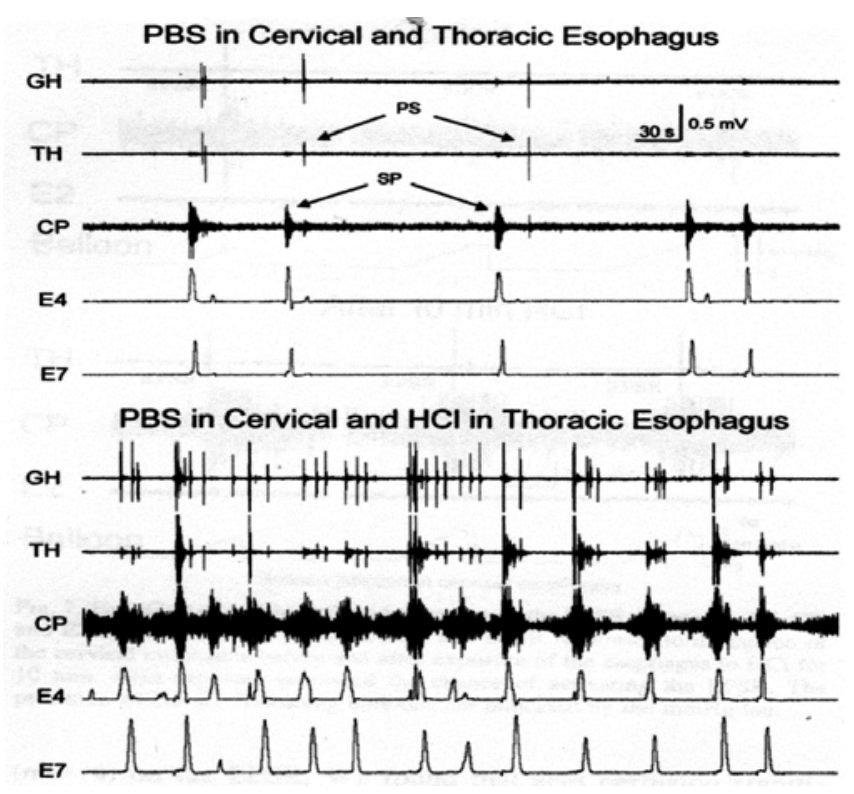

Figure 13 The effect of $\mathrm{HCl}$ infusion on activation of EPSR. This figure shows that while the infusion of PBS into the entire esophagus in a decerebrate cat had a minimal effect on the activation of EPSR, $\mathrm{HCl}$ infusion into the thoracic esophagus strongly activated EPSR. GH, geniohyoideus; $\mathrm{TH}$, thyrohyoideus; $\mathrm{CP}$, cricopharyngeus.

\subsubsection{Function}

The primary function of the EPSR is to prevent SER by clearing the pharynx and the esophagus. The effects of EPSR serve a more important function in human infants and animals than human adults because of their anatomical and physiological differences [56, 72-74]. In adult humans, the larynx has descended placing it further away from the larynx than in infant humans or animals [56, 72-74]. If GER were to occur in a human infant or animal such that the refluxate approaches the UES and threatens SER, a pharyngeal swallow would be a safer response than secondary peristalsis as their pharynx is close to the larynx and has a smaller capacity [56, 72-74]. Infant humans, in particular, often have significant GER that approaches the UES and triggers SER.

\subsubsection{Receptors}

The EPSR is blocked by local anesthesia of the esophageal mucosa, and it can be activated by afferent stimulation of the RLN just caudal to the cricoid cartilage (RLNc [56]). Considering that 1) local anesthesia of the mucosa does not block EUCR [9], 2) the EPSR is activated by slow tension applied to the esophageal lumen [56], 3) the EPSR is sensitized by acid application to the esophageal mucosa [56], and 4) no other esophageal reflexes are activated by afferent stimulation of the RLNc [56], it is concluded that the receptors mediating the EPSR are the esophageal tension/mucosal (T/M) receptors [21].

\subsubsection{Innervation}

As discussed above, the afferent innervation of the EPSR is the RLNc, which connects to the SLN before the SLN merges with the vagus nerve, and the efferents are the usual efferent innervations involved in the pharyngeal swallow $[41,75,76]$. 


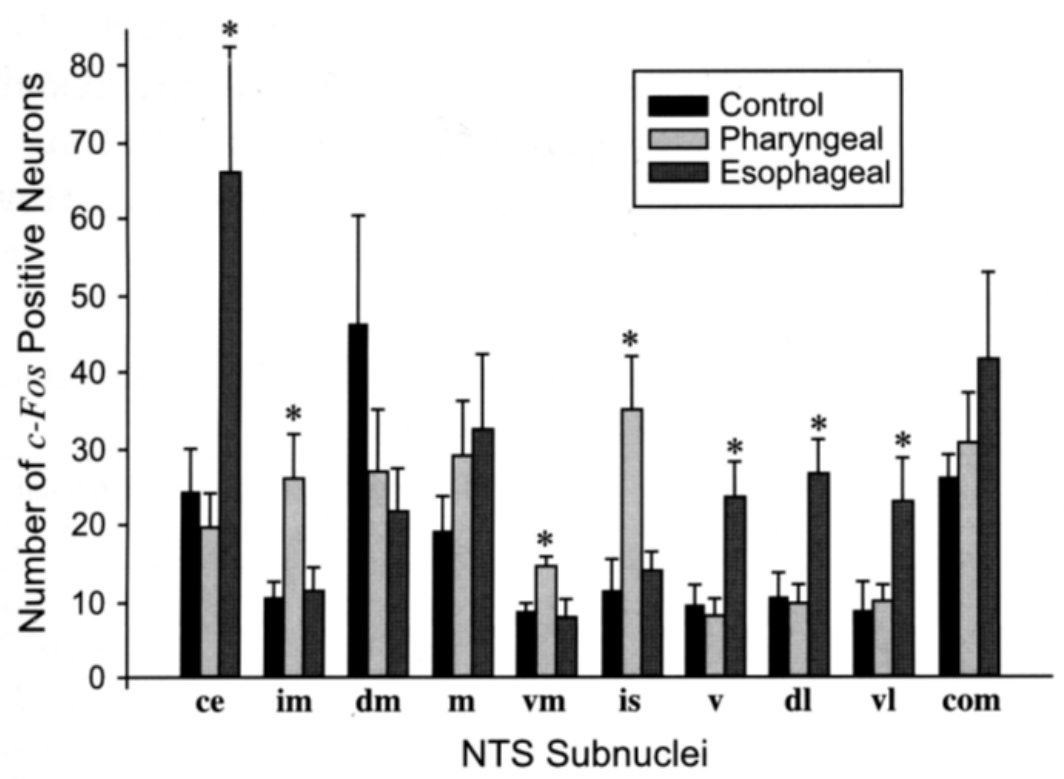

Figure 14 Graph showing the number of neurons activated during different phases of swallowing. Different phases activate different sets of neurons in NTS subnuclei in the brain stem [78]. See Figure 6 for definition of symbol.

\subsubsection{Neural Control Mechanisms}

EPSR can occur in a decerebrate animal/cat and requires activation of vagal afferent (RLNp) [56]; therefore, it could be generated by the brain stem. The EPSR response is simply the pharyngeal swallow. Hence, the motor control of the EPSR is probably in the same nuclei that control the pharyngeal swallow activated by other sensory stimuli $[77,78]$. The unique aspect of the EPSR is that it involves only the pharyngeal phase of swallowing whereas other stimuli tend to activate the entire swallowing process $[76,77]$. This finding corroborates other observations in previous studies [78] that established that the pharyngeal and esophageal phases of swallowing are distinct and are mediated by different sets of brain stem nuclei (Figure 14).

\subsubsection{Dysfunction}

Although there are no known dysfunctions of the EPSR, studies on decerebrate cats [79] have shown that the sensitivity to activation of the EPSR is heightened in a supine body position (Figure 15). In sudden infant death syndrome (SIDS), a disorder unique to infants, an increased incidence of infants in the prone position was observed [80-82]. One of the hypothesized causes of SIDS is laryngeal chemoreflex-induced apnea due to supra-esophageal reflux of acid [83]. Since the pharynx is closer to the larynx and is smaller in human infants due to the lack of laryngeal descent $[69,72,74]$, the EPR in the infant humans is more likely to have laryngeal reflux. The EPSR is a safe and effective tool for emptying the pharynx; therefore, it is highly beneficial for human infants and animals to have the EPSR. Since placing animals in the supine position sensitizes activation of the EPSR [79], it could prevent EPR of acid from contacting the larynx and causing apnea and SIDS. 

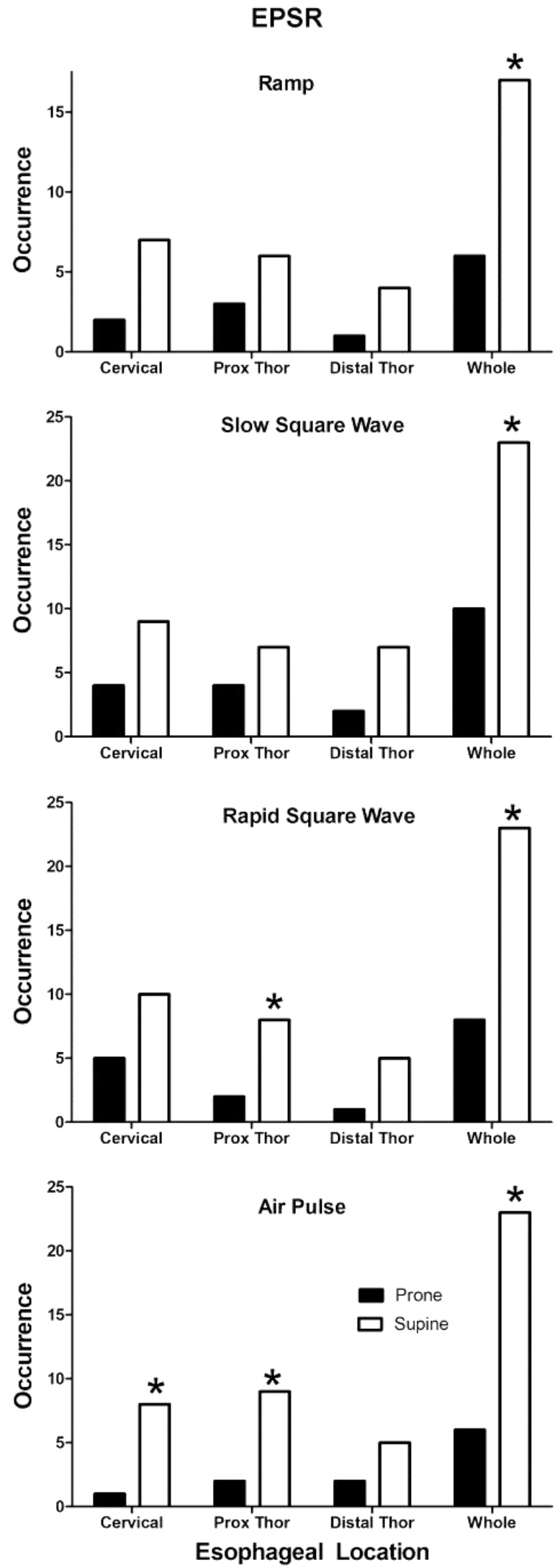

Figure 15 The effect of body position on activation of EPSR. The figures demonstrate that activation of the EPSR is more sensitive in the supine than prone position (in cervical), regardless of the stimulus employed [79]. 


\subsection{Esophageal Inhibition: Pharyngo-Esophageal Inhibitory Reflex}

\subsubsection{Stimulus and Response}

Mechanical stimulation of the pharynx using fluid or air inhibits further progression of esophageal peristalsis [67, 84-91].

\subsubsection{Function}

The role of peristalsis is to empty the esophagus of intraluminal contents. However, to activate esophageal peristalsis, ongoing motor activity of the esophagus must be stopped in order to prevent obstruction of the flow of intraluminal contents. This function is performed by the pharyngo-esophageal inhibitory reflex (PEIR).

\subsubsection{Receptors}

The PEIR $[67,84-91]$ is activated by minute quantities of water in the pharynx. So, the initiating receptors can be pharyngeal, mucosal tension receptors.

\subsubsection{Innervation}

The afferent innervation of the PEIR is probably the GPN $[68,91]$. The efferents of the PEIR depend on the muscle type. The PEIR afferents likely inhibit the brain stem motor control of the striated muscle esophagus to inhibit striated muscle esophageal motor activity. On the other hand, the PEIR efferents to the smooth muscle are probably vagal inhibitory neurons.

\subsubsection{Neural Control Mechanisms}

As the PEIR probably requires GPN afferents [68, 91] and functions in decerebrate animals [91], it might be controlled by the brain stem. However, more studies are warranted to validate this hypothesis.

\subsubsection{Dysfunction}

Without PEIR, the transport of esophageal contents may be significantly hampered, but such disorders have not been reported so far in the literature. There is a need for further studies to determine the disorders of esophageal peristalsis and understand the role of dysfunction of the PEIR in these disorders.

\subsection{EGCR: Esophago-Glottal Closure Reflex}

\subsubsection{Stimulus and Response}

Stimulation of the esophagus causes glottal closure in humans in the same manner as the esophagus activates belching [92-94] and activates the thyroarytenoideus and cricothyroideus muscles (Figure 16) in the decerebrate cat [94]. 


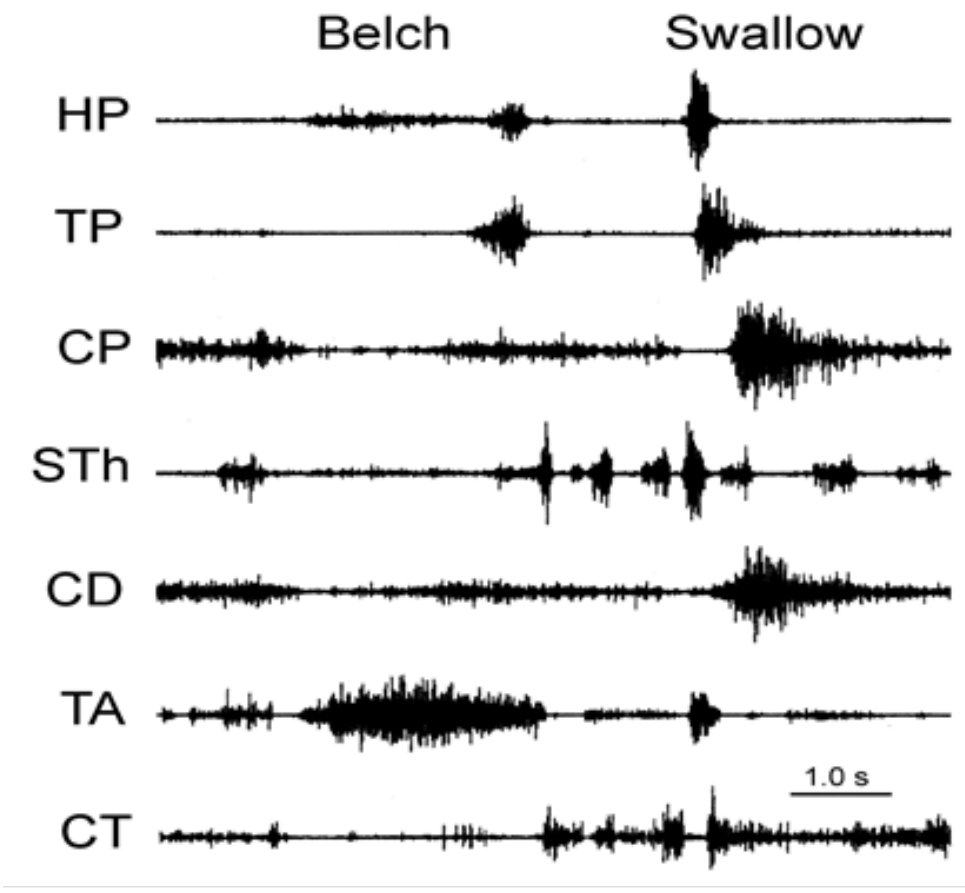

Figure 16 The esophago-glottal contractile reflex (EGCR). This figure depicts the pharyngeal and laryngeal responses during a spontaneous belch in a chronically instrumented awake dog [51]. The belch is associated with the inhibition of CP EMG, but also with strong activation of the TA, the primary muscle closing the glottis. The different muscles (on the right side) involved in the swallowing mechanism are shown in the figure. HP, hyopharyngeus; TP, thyropharyngeus (called inferior pharyngeal constrictor [IPC] in humans); $C P$, cricopharyngeus; STh, sternothyroideus; $C D$, cricoarytenoid dorsalis; TA, thyroarytenoideus; CT, cricothyroideus.

\subsubsection{Function}

The EGCR initiates closure of the larynx to prevent aspiration. EGCR is one of the primary subreflexes of the belch response [92, 93].

\subsubsection{Receptors}

The receptors that mediate the EGCR appear similar to those which mediate the EURR, i.e., the rapidly adapting tension receptors of the esophageal mucosa [6]. This hypothesis is based on the finding that in some studies [9] the removal of esophageal mucosa and submucosa or luminal application of lidocaine blocked the EURR and also the EGCR, i.e., activation of the thyroarytenoideus muscle during belching.

\subsubsection{Innervation}

The afferent nerve for the EGCR is the same as the EURR, which are vagal afferents through the RLN, SLN, and nodose ganglion [9, 38-40]. The efferent nerve is the motor nerve for the laryngeal muscles, which is the SLN [29] for all except for the cricothyroideus that is mediated by the RLN [29-31]. 


\subsubsection{Neural Control Mechanism}

The brainstem is the control center of the EGCR because the EGCR is mediated by vago-vagal innervation and is not blocked by decerebration [9]. Since the EGCR is a subset of the belch responses as in the EURR, it may be mediated by the same brainstem nuclei as are mediated by the EURR (as shown in Figure 16).

\subsubsection{Dysfunction}

The dysfunction of the EGCR has not yet been reported in the literature.

\subsection{Esophago-Airway Reflex Responses}

\subsubsection{Stimulus and Response}

Acid stimulation of the esophagus activates three airway responses, which are part of one functional process [95]. Esophageal acid exposure decreases bronchial diameters of the smaller low-resistance airways (Figure 17), decreases tracheal mucociliary transport, and increases tracheobronchial mucus secretion (Figure 18). Tracheal mucociliary transport is significantly affected by the level of mucus lining the airway; therefore, the decrease in mucociliary transport may be due to the increase in mucus output. In this process, only two reflex responses: the increase in tracheal mucus output and constriction of the smaller diameter airways get activated. The mucus response consists of neutral mucosubstances secreted by the apocrine glands [96].

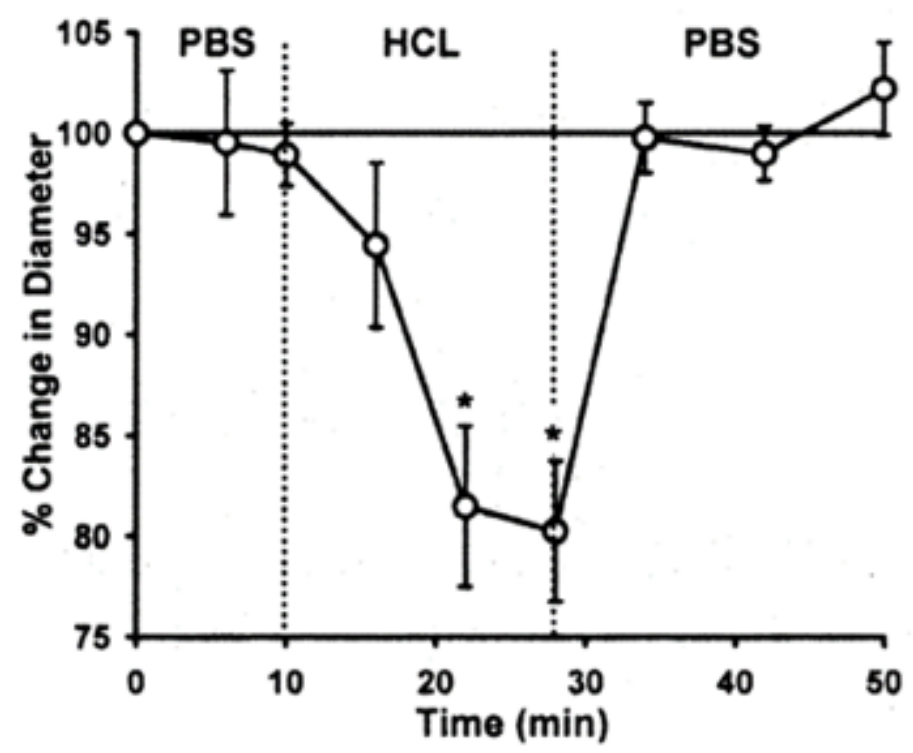

Figure 17 Effect of esophageal acid exposure on airway diameter. The average change in the diameter of four different sized airways as a percentage of control during change from $0.1 \mathrm{~m} \mathrm{PBS}$ to $0.1 \mathrm{~N} \mathrm{HCl}$ and back is shown on Y-axis [95]. 


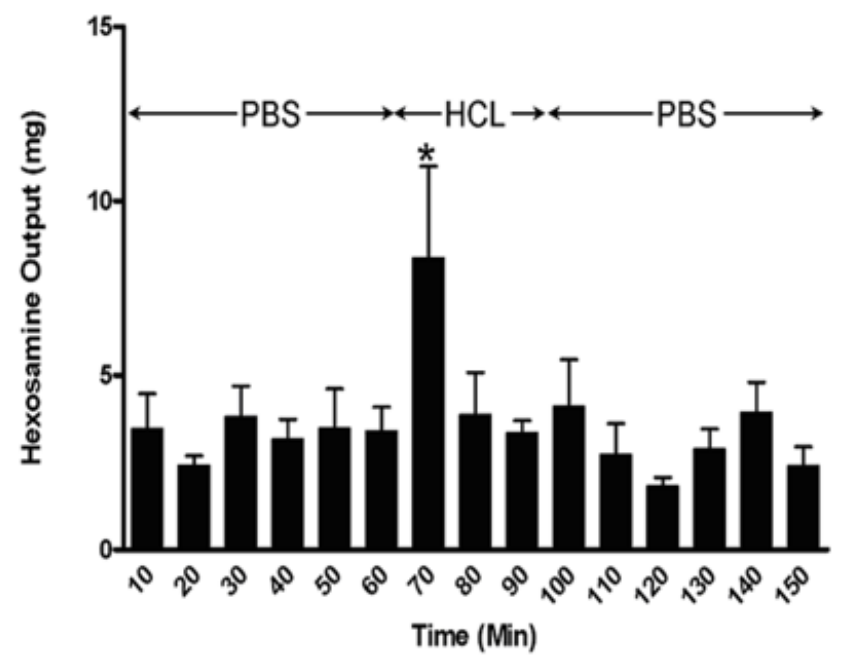

Figure 18 Effect of esophageal acid exposure on mucus output from the tracheobronchial tree. Hexosamine output was used as a measure of mucus secretion [95].

\subsubsection{Function}

The primary function of the esophago-airway reflex responses is airway protection from the microaspiration of gastro-esophageal acid reflux. The secretion of mucus neutralizes the $\mathrm{HCl}$ and inhibits mucociliary transport. It can be hypothesized that airway constriction assists in the rapid secretion of mucus as muscle contraction causes apocrine secretion. Besides, airway constriction increases the effectiveness of coughing while not affecting lung resistance or compliance. Coughing through narrower airways increases the airflow velocity thereby facilitating the removal of the acid from the airway [95].

\subsubsection{Receptors}

The esophageal receptors mediating the airway responses remain underinvestigated. As the stimulus is luminal acid, it is hypothesized that the receptors may be mucosal chemoreceptors.

\subsubsection{Innervation}

Evidence suggests that the reflexes controlling the two different responses have different neural innervation. The airway constriction response is blocked by vagotomy and atropine and is mediated by a vagal cholinergic pathway [96]. On the other hand, the mucus response is blocked by atropine, but not through vagotomy. Besides, the airway closest to the acid-exposed esophagus has a much greater mucus and mucociliary response [96]. Considering that a direct neural pathway from the esophagus to the airway exits [97], it can be hypothesized that the airway mucus response is mediated by this local neural pathway.

\subsubsection{Neural Control Mechanisms}

The airway muscle response to esophageal acidification is mediated by the vagus nerve and is thus regulated by the CNS, but the specific nuclei involved are unknown. On the other hand, the 
mucus response to esophageal acidification is probably mediated by a direct pathway through the tracheal ganglia $[96,97]$ as part of the innate mucosal defense system of the airway [98].

\subsubsection{Dysfunction}

The reason for the dysfunction of the innate mucosal defense system remains undetermined, but it appears that the innate mucosal defense system may play some role in asthma [99].

\subsection{Reverse Peristalsis}

\subsubsection{Stimulus and Response}

Rapid distension of the esophagus that stimulates belching also activates reverse peristalsis [50, 51] of the striated muscle esophagus (Figure 19). This mechanism has been documented only in animal studies, though it also occurs in humans. However, it probably has not been recorded in humans because of the short length of the striated muscle esophagus and very few studies on the human striated muscle esophagus have been conducted. More clarity is needed on whether this reverse peristalsis occurs due to reasons other than as part of belching. As other subreflexes occur independently of belching, this subreflex may occur independently of belching.

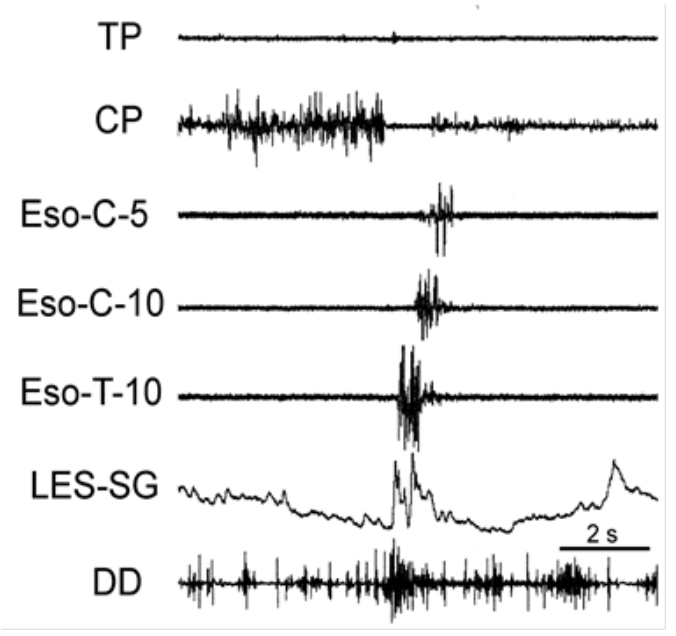

Figure 19 Reverse peristalsis. This figure shows the responses of the esophagus during the spontaneous belch in a chronically instrumented awake dog [51]. In the middle of LES relaxation, the diaphragm dome contracts, followed by a wave of activation of the esophagus, which begins at the LES and rapidly progresses to the cervical esophagus. This wave however does not continue to the CP. The entire esophagus of the dog is striated muscle. All recordings are EMG but the LES, which is a recording of tension from an implanted strain gauge (SG). TP, thyropharyngeus; CP, cricopharyngeus; EsoC/T-\#; cervical or thoracic esophagus \# $\mathrm{cm}$ from the CP. LES, lower esophageal sphincter; DD, diaphragmatic dome.

\subsubsection{Function}

The function of reverse peristalsis is to help move the esophageal contents orally (Figure 19). This response has been observed only in carnivores during belching and in the ruminants during 
rumination, though it may occur in humans as well. Studies have failed to unravel why reverse peristalsis occurs in the striated muscle esophagus. One possible reason may be the relatively longer length of the esophagus in animals compared to in humans. As the esophagus in animals (cats/dogs, etc.) is longer than in humans, it may require the added aboral effect of reverse peristalsis to move esophageal contents to the oral cavity.

Reverse peristalsis of the long striated muscle esophagus may play a prominent function in animals. Such functions are redundant in humans. Ruminants need this mechanism for proper rumination. Wild carnivores need not make unnecessary and unexpected noises for their selfprotection, which could expose them to their prey or prevent them from being preyed upon. Belching that requires a significant push of air from the stomach to the esophagus can cause a loud noise as observed in humans also. This situation is absent in carnivores as they require only a small push of air as the primary reflux motion is produced by reverse peristalsis. Belching is often distinctly heard in humans, not in animals, even though animals also belch [50].

\subsubsection{Receptors}

The receptors for activation of reverse peristalsis have not been identified yet but they may be the same receptors that mediate the belch response, i.e., the mucosal rapidly adapting tension receptors.

\subsubsection{Innervation}

The nature of the afferents and efferents of the reverse peristalsis remains uninvestigated, but vago-vagal reflex may be similar to afferents and efferents of the reverse peristalsis.

\subsubsection{Nervous System Mechanism}

It remains unexplored how CNS nuclei regulate reverse peristalsis. As in the case of other subreflexes of the belch, such peristalsis may be mediated by the brain stem nuclei as revealed by c-fos activation in response to stimulation of the esophagus that had activated the EURR [43].

\subsubsection{Dysfunction}

There are no known conditions arising from dysfunction of reverse peristalsis

\section{Lower Esophageal Sphincter Reflexes}

\subsection{LES Inhibition: Pharyngo-LES Inhibitory Reflex (PLIR) and Esophago-LES Inhibitory Reflex (ELIR).}

\subsubsection{Stimulus and Response}

The esophageal peristaltic wave causes contraction of the longitudinal muscle of the esophagus, which stretches the esophagus distal to the peristaltic wave and this longitudinal stretch causes relaxation of the LES, i.e., the esophago-LES Inhibitory reflex (ELIR) [100-102]. The ELIR can be activated independently of peristalsis by mild esophageal distension, which activates longitudinal tension of the distal esophagus and causes LES relaxation [103-105]. In the PLIR, pharyngeal 
stimulation causes contraction of the esophageal longitudinal muscle, which, as in peristalsis or ELIR, relaxes the LES [106-108]. Although this review has discussed only the reflexes activated by esophageal stimulation or esophageal responses activated by reflexes activated from other organs, it should be recognized that the crural diaphragm is involved in the function of the LES $[104,109]$. The intraluminal pressure of the esophagus within the LES is also affected by contractions of the crural diaphragm, and the crural diaphragm participates in the function of the LES [109]. However, a difference in the role of the crural diaphragm in the PLIR versus ELIR can be noticed. The crural diaphragm is activated during the ELIR $[103,104]$ but not the PLIR [108], although the mechanism of this difference remains poorly understood.

\subsubsection{Function}

During the progression of esophageal peristalsis, the PLIR and ELIR cause LES relaxation. While the PLIR initiates LES relaxation, the ELIR ensures that the LES remains relaxed throughout the entire peristaltic process.

\subsubsection{Receptors}

The PLIR [106-108] is activated by small amounts of water in the pharynx. Hence, it is likely that the initiating receptors are pharyngeal mucosal tension receptors. On the other hand, the ELIR initiating receptors are probably muscular tension receptors of the esophagus as the response requires balloon distension of the esophagus [103-104]. This difference in receptor types may explain why the PLIR does not affect the crural diaphragm, but the ELIR does. Further studies are suggested to define this difference. It has been hypothesized that the receptors responsible for the relaxation of the LES are mechanoreceptive inhibitory neurons of the enteric nervous system (ENS) of the smooth muscle esophagus or LES [104, 106, 110]; however, no such esophageal mechanoreceptors could be identified or characterized yet.

\subsubsection{Innervation}

It has been found that the ELIR does not depend on the CNS or ENS [104], but is a local reflex response, which does not involve extrinsic afferent or efferent neural pathways. On the other hand, the afferents for the PLIR and PUCR are probably the same which are located in the GPN [68, 91]. The efferents of the PLIR, which activate esophageal longitudinal muscles may reside within the vagus nerve.

\subsubsection{Neural Control Mechanism}

Since the PLIR probably requires GPN afferents $[68,91]$ and functions in decerebrate animals [91], it must be controlled by the brain stem. Further studies are warranted to validate this hypothesis. On the other hand, the remainder of the PLIR and the ELIR involves intrinsic innervation [104], and this must include neurons of the ENS of the smooth muscle portion of the esophagus or LES. 


\subsubsection{Dysfunction}

PLIR and ELIR play a role in opening the LES and may be activated too often or at an inopportune time leading to gastro-esophageal reflux disease (GERD). However, due to a lack of clarity on the activation and timing of PLIR and ELIR, the current review paper highlights the need for more studies on this issue.

\subsection{Gastro-LES Inhibitory Reflex (GLIR)}

\subsubsection{Stimulus and Response}

Distension of the proximal stomach causes the relaxation of the LES as well as the crural diaphragm (CD) [111-114].

\subsubsection{Function}

The function of belching is to eliminate excess gas within the upper digestive tract and the first phase of the belch response is the elimination of the barrier between the stomach and esophagus to allow the excess air bolus to escape from the stomach. This function is served by the GLIR [111113]. The GLIR has also been referred to as the transient relaxation [52] of the LES (TLESR). The TLESR is independent of the transient relaxation of the UES, which also occurs during belching and is followed by TLESR [115]. The gas that escapes the stomach due to TLESR activates receptors in the esophagus, thereby activating EURR (Figure 20).

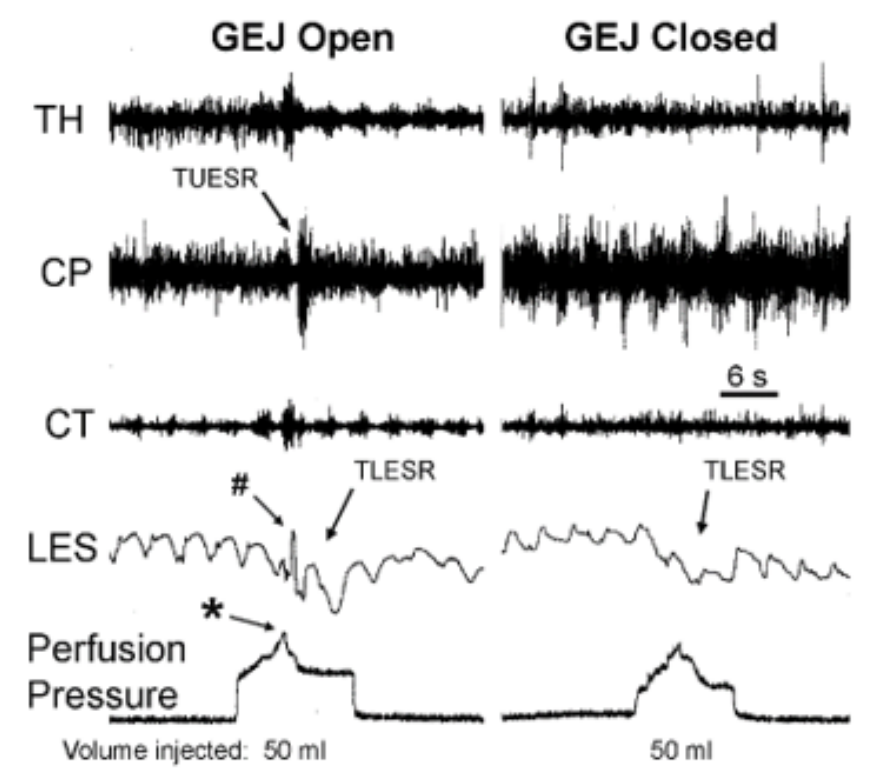

Figure 20 The effects of the closure of the gastroesophageal junction during gastric air injection on the UES and LES in thoractomized animals. In the above figure, injection of air into the proximal stomach caused TUESR and TLESR when the GEJ was open, but only TLESR when the GEJ was closed. Therefore, gastric gas escape activates the TUESR, and gastric distension activates the TLESR. GEJ, gastroesophageal junction; TH, thyrohyoideus; CP, cricopharyngeus; CT, cricothyroideus; LES, lower esophageal sphincter. 


\subsubsection{Receptors}

Mechanoreceptors that are responsive to stretch rather than tension of the proximal stomach mediate the GLIR mechanism [116].

\subsubsection{Innervation}

The GLIR is mediated by a vago-vagal pathway as vagotomy blocked gastro-esophageal gas reflux as well as the GLIR [117].

\subsubsection{Neural Control}

The neural control mechanism of the GLIR has not been explored yet, but since it is mediated by a vago-vagal pathway [117], it may be CNS-mediated.

\subsubsection{Dysfunction}

Though the GLIR is an integral part of the belch response, activation of the GLIR can also cause gastro-esophageal reflux $[118,119]$ and also contribute to GERD $[109,113]$.

\section{Conclusion}

To sum up, in this review paper, we have delved deep into mechanisms, functions, dysfunctions, receptors, and innervations associated with several key reflexes of the esophagus. Also, this paper has thrown light associating these reflexes with several mechanisms of belching, swallowing, peristalsis in animals primarily. Since only a few studies are available on humans on this subject, this review paper highlights the significance of undertaking larger human studies that would help understand several associated conditions, neural and reflexive pathways associated. This review will be important for the medics, research professionals, and clinicians to understand and devise suitable for timely interventions of gastrointestinal and esophageal conditions that probably contribute to over $70 \%$ of deaths across the planet because gastro/esophageal dysfunctions are associated with the brain, cardiac and liver-related disorders, including carcinogenesis that contributes to over $90 \%$ deaths across the world today.

\section{Author Contributions}

Ivan M. Lang did all work.

\section{Competing Interests}

The author has declared that no competing interests exist.

\section{References}

1. Park H, Conklin JL. Neuromuscular control of esophageal peristalsis. Curr Gastroenterol Rep. 1999; 1: 186-197.

2. Christensen J. Mechanisms of secondary esophageal peristalsis. Am J Med. 1997; 103: 44-46. 
3. Eslami MH, Richards WG, Sugarbaker DJ. Esophageal physiology. Chest Surg Clin N Am. 1994; 4: 635-652.

4. Lang IM. The physiology of eructation. Dysphagia. 2016; 31: 121-133.

5. Lang IM. Digestive tract motor correlates of vomiting and nausea. Can J Physiol Pharmacol. 1990; 68: 242-253.

6. Creamer B, Schlegel J. Motor responses of the esophagus to distension. J Appl Physiol. 1957; 10: 498-504.

7. Enzmann DR, Harell GS, Zboralske FF. Upper esophageal responses to intraluminal distension in man. Gastroenterology. 1977; 72: 1292-1298.

8. Williams D, Thompson DG, Heggie L, Banceewicz J. Responses of the human esophagus to experimental intraluminal distension. Am J Physiol. 1993; 265: 196-203.

9. Lang IM, Medda BJ, Shaker R. Mechanisms of reflexes induced by esophageal distension. Am J Physiol. 2001; 281: 1246-1263.

10. Lang IM, Medda BK, Shaker R. Characterization and mechanism of the esophago-esophageal contractile reflex of the striated muscle esophagus. Am J Physiol. 2019; 317: 304-314.

11. Paterson WG. Neuromuscular mechanisms of esophageal responses at and proximal to a distending balloon. Am J Physiol. 1991; 260: 148-155.

12. Babaei A, Dua K, Naini SR. Response of the upper esophageal sphincter to esophageal distension is affected by posture, velocity, and composition of the infusate. Gastroenterology. 2012; 142: 734-743.

13. Lang IM, Medda BK, Shaker R. Effects of esophageal acidification on esophageal reflexes controlling the upper esophageal sphincter. Am J Physiol. 2019; 316: 45-54.

14. Babaei A, Venu M, Naini R, Gonzaga J, Lang IM, Massey BT, et al. Impaired upper esophageal sphincter reflexes in patients with supraesphageal reflux disease. Gastroenterology. 2015; 149: 1381-1391.

15. Kahrilas PJ, Dodds WJ, Dent J, Logemann JA, Shaker R. Upper esophageal sphincter function during deglutition. Gastroenterology. 1988; 95: 52-62.

16. Martin BW, Logemann JA, Shaker R, Dodds WJ. Coordination between respiration and swallowing: Respiratory phase relationships and temporal integration. J Appl Physiol. 1994; 76: 714-723.

17. Christensen J, Lund GF. Esophageal responses to distension and electrical stimulation. J Clin Investigation. 1969; 48: 408-419.

18. Paterson WG, Rattan S, Goyal RK. Esophageal responses to transient and sustained esophageal distension. Am J Physiol. 1988; 255: 587-595.

19. Mei N. Mechanoreceptors of vagal digestive tract neurons in the cat. Exp Brain Res. 1970; 11: 502-514.

20. Harding R, Titchen DA. Chemosensitive vagal endings in the esophagus of the cat. J Physiol. 1975; 247: 52-53.

21. Page AJ, Blackshaw LA. An in vitro study of the properties of vagal afferent fibers innervating the ferret oesophagus and stomach. J Physiol. 1998; 512: 907-916.

22. Rodrigo J, Hernandez CJ, Vidal MA, Pedrosa JA. Vegetative innervation of the esophagus. III. Intraepithelial endings. Acta Anat. 1975; 92: 242-258.

23. Clerc N, Mei N. Vagal mechanoreceptors located in the lower esophageal sphincter of the cat. J Physiol. 1983; 386: 487-498. 
24. Page AJ, Martin CM, Blackshaw LA. Vagal mechanoreceptors and chemoreceptors in mouse stomach and esophagus. J Neurophysiol. 2002; 87: 2095-2103.

25. Rodrigo J, Hernandez CJ, Vidal MA, Pedrosa JA. Vegetative innervation of the esophagus. II. Intraganglionic laminar endings. Acta Anat. 1975; 92: 79-100.

26. Satchell PM. Canine oesophageal mechanoreceptors. J Physiol. 1984; 346: 287-300.

27. Zagorodnyuk VP, Brookes SJ. Transduction sites of vagal mechanoreceptors in the guinea pig esophagus. J Neurosci. 2000; 20: 6249-6255.

28. Seikizawa S, Ishikawa T, Saint'Ambrogio FB, Saint'Ambrogio G. Vagal esophageal receptors in anesthetized dogs: Mechanical and chemical responsiveness. J Appl Physiol. 1999; 86: 12311235.

29. Gray H, Gross CM. Anatomy of the human body. Philadelphia, PA: Lea and Febiger; 1968.

30. Steven CE. Comparative physiology of the vertebrate digestive system. Cambridge: Cambridge University Press; 1988.

31. Evans HE, Christensen GC. Miller's anatomy of the dog. Philadelphia, PA: W.B. Saunders Company; 1979.

32. Horsbaugh DB, Heath JP. Atlas of cat anatomy. Stanford, CA: Stanford University Press; 1950.

33. Lang IM, Medda BK, Jadcherla S, Shaker R. The role of the superior laryngeal nerve in esophageal reflexes. Am J Physiol. 2012; 3032: 1445-1457.

34. Reynolds RP, Effer GW, Bendeck MP. The upper esophageal sphincter in the cat: The role of central innervation assessed by transient vagal blockade. Can J Physiol Pharmacol. 1987; 65: 96-99.

35. Freiman JM, El-Sharkaway TY, Diamant NE. Effect of bilateral vagosympathetic nerve blockade on response of the dog upper esophageal sphincter (UES) to intraesophageal distension and acid. Gastroenterology. 1981; 81: 78-84.

36. Fukunaga $\mathrm{Y}$, Higashino M, Osugi $\mathrm{H}$, Tokuhara $\mathrm{T}$, Kinoshita $\mathrm{H}$. Function of the upper esophageal sphincter after denervation of recurrent laryngeal nerves and intramural nerves of the cervical esophagus in dogs. Nihon Geka Gakkai Zasshi. 1994; 95: 643-654.

37. Grundy D, Scratcherd T. Sensory afferents from the gastrointestinal tract. Compr Physiol. 2010; 6: 593-620.

38. Hamond CS, Davenport PW, Hutchinson A, Otto RA. Motor innervation of the cricopharyngeus muscle by the recurrent laryngeal nerve. J Appl Physiol. 1997; 831: 89-94.

39. Mu L, Sanders I. Neuromuscular organization of the human upper esophageal sphincter. Am Otol Rhinol Laryngol. 1998; 107: 370-377.

40. Prades JM, Timoshenko AP, Asanau A, Gavid M, Benakki H, Dubois MD, et al. The cricopharyngeal muscle and the laryngeal nerves: Contribution to the functional anatomy of swallowing. Morphologie. 2009; 93: 35-41.

41. Hwang K, Grossman MI, Ivy AC. Nervous control of the cervical portion of the esophagus. Am J Physiol. 1948; 154: 343-357.

42. Kobler JB, Datta S, Goyal RK, Benecchi EJ. Innervation of the larynx, pharynx, and upper esophageal sphincter of the rat. J Comp Neurol. 1994; 349: 129-147.

43. Lang IM, Medda BK, Shaker R. Differential activation of medullary vagal nuclei caused by stimulation of different esophageal mechanoreceptors. Brain Res. 2011; 1368: 119-133. 
44. Szczesniak MM, Fuentealba SE, Burnett A, Cook IJ. Differential relaxation and contractile responses of the human upper esophageal sphincter mediated by interplay of mucosal and deep muscular activation. Am J Physiol-Gastr L. 2008; 294: 982-988.

45. Kahrilas PJ, Dodds WJ, Dent J, Wyman JB, Hogan WJ, Arndorfer RC. Upper esophageal sphincter function during belching. Gastroenterology. 1986; 91: 133-140.

46. Shaker R, Dodds WJ, Ren J, Hogan WJ, Arndorfer RC. Esophago-glottal closure reflex: A mechanism of airway protection. Gastroenterology. 1992; 102: 857-861.

47. Shaker R, Ren J, Kern M, Dodds WJ, Qi LK. Mechanism of airway protection and upper esophageal opening during belching. Am J Physiol. 1992; 262: 621-628.

48. Shaker R, Ren J, Medda BK, Lang IM, Cowles V, Jaradeh S. Identification and characterization of the esophago-glottal closure reflex in a feline model. Am J Physiol. 1994; 266: 1476-153.

49. Lang IM. Upper esophageal sphincter. GI Motility Online. 2006. Available From: https://www.nature.com/gimo/contents/pt1/full/gimo12.html.

50. Lang IM. The physiology of eructation. Dysphagia. 2016; 31: 121-133.

51. Lang IM, Medda BK, Shaker R. The digestive and respiratory tract motor responses associated with eructation. Am J Physiol-Gastr L. 2013; 304: 1044-1053.

52. Pandolfino JE, Ghosh SK, Zhang Q, Han A, Kahrilas PJ. Upper esophageal function during transient lower esophageal relaxation (tLOSR), it is mainly about microburps. Neurogastroenterol Motil. 2007; 19: 202-210.

53. Hemmink GJ, Bredenoord AJ, Weusten BL, Timmer R, Smout AJ. Supragastric belching in patients with reflux symptoms. Am J Gastroenterol. 2009; 104: 1992-1997.

54. Bredenoord AJ, Weusen BL, Sifrin D, Timmer R, Smout AJ. Aerophagia, gastric, and supragastric belching: A study using intraluminal electrical impedance monitoring. Gut. 2004; 53: 1561-1565.

55. Kessing BF, Bredenoord AJ, Smout AJ. The pathophysiology, diagnosis, and treatment of excessive belching syndromes. Am J Gastroenterol. 2014; 109: 1196-1203.

56. Lang IM, Medda BK, Shaker R. Characterization and mechanisms of the supragastric belch in the cat. Am J Physiol-Gastr L. 2017; 313: 220-229.

57. Hamdy S. Role of cerebral cortex in the control of swallowing. GI Motility Online. 2006. Available From: https://www.nature.com/gimo/contents/pt1/full/gimo8.html.

58. Fukushima SI, Shuingai T, Kitagawa J, Takahashi Y, Taguchi $Y$, Noda T, et al. Role of the pharyngeal branch of the vagus nerve in laryngeal elevation and UES pressure during swallowing in rabbits. Dysphagia. 2003; 18: 58-63.

59. Miller AD, Ruggiero DA. Emetic reflex arc revealed by expression of the immediate-early gene c-fos in the cat. J Neurosci. 1994; 14: 871-888.

60. Miller AD, Leslie RA. The area postrema and vomiting. Front Neuroendocrinol. 1994; 15: 301320.

61. Borison HL, Wang SC. Functional localization of central coordinating mechanism for emesis in cat. J Neurophysiol. 1949; 12: 305-311.

62. Fukuda $\mathrm{H}$, Koga $\mathrm{T}$. The Botzinger complex as the pattern generator for retching and vomiting. Neurosci Res. 1991; 12: 471-485.

63. Koga T, Fukuda $\mathrm{H}$. Neurons in the nucleus of the solitary tract mediating inputs from emetic vagal afferents and the area postrema to the pattern generator of emetic act in dogs. Neurosci Res. 1992; 14: 166-179. 
64. Koga T, Kobashi M, Mizutani M, Tsukomoto G, Matsuo R. Area postrema mediates gastric motor responses induced by apomorphine in rats. Brain Res. 2003; 960: 120-132.

65. Kawachi M, Hori N, Tsakei M, Kurimoto T, Akaike N, Ito Y. Gastric relaxation induced by electrical or chemical stimulation of the area postrema in the rat. Gen Physiol Biophysics. 2008; 27: 243-252.

66. Shaker R, Ren J, Xie P, Lang IM, Bardan E, Sui Z. Characterization of the pharyngo-UES contractile reflex in humans. Am J Physiol-Gastr L. 1997; 2373: 854-858.

67. Bardan E, Saeian K, Xie P, Ren J, Kern M, Dua K, et al. Effect of pharyngeal stimulation on the motor function of the esophagus and its sphincters. Laryngoscope. 1999; 109: 437-441.

68. Medda BK, Lang IM, Layman R, Hogan WJ, Dodds WJ, Shaker R. Characterization and quantification of a pharyngo-UES contractile reflex in cats. Am J Physiol-Gastr L. 1994; 267: 972-983.

69. Jadcherla SR, Duing HQ, Hoffman RG, Shaker R. Esophageal body and upper esophageal motor responses to esophageal provocation during maturation in preterm newborns. J Pediatr. 2003; 143: 31-38.

70. Jadcherla SR, Hoffman RG, Shaker R. Effect of maturation of the magnitude of mechanosensitive and chemosensitive reflexes in the premature human esophagus. J Pediatr. 2006; 149: 77-82.

71. Madsen T, Wallin L, Boesby S, Larsen VH. Oesophageal peristalsis in normal subjects: Influence of $\mathrm{pH}$ and volume during imitated gastro-oesophageal reflux. Scand J Gastroenterol. 1983; 18: 513-518.

72. Laitman JT, Reidenberg JS. Specialization of the human upper respiratory and upper digestive systems as seen through comparative and developmental anatomy. Dysphagia. 1993; 8: 318325.

73. Palmer JB, Rudin NJ, Laga G, Crompton AW. Coordination of mastication and swallowing. Dysphagia. 1992; 7: 187-200.

74. Jadcherla SR, Gupta A, Stoner E, Fernandez S, Shaker R. Pharyngeal swallowing: Defining pharyngeal and upper esophageal sphincter relationship in human neonates. J Pediatr. 2007; 151: 597-603.

75. Goyal RK, Chaudhury A. Physiology of normal esophageal motility. J Clin Gastroenterol. 2008; 42: 610-619.

76. Thexton AJ. Mastication and swallowing: An overview. Brit Dental J. 1992; 173: 197-206.

77. Ertekin C, Aydogdu I. Neurophysiology of swallowing. Clin Neurophysiol. 2003; 114: 22262244.

78. Lang IM. Brain stem control of the phases of swallowing. Dysphagia. 2009; 24: 333-348.

79. Lang IM, Medda BK, Shaker R, Jadcherla S. The effects of body position on esophageal reflexes in cats: A possible mechanism of SIDS? J Pediatr. 2018; 83: 731-738.

80. Dwyer T, Ponsonby AL. Sudden infant death syndrome and prone sleeping position. Ann Epidemiol. 2009; 19: 245-249.

81. Gilbert R, Salanti G, Harden M, See S. Infant sleeping position and the sudden infant death syndrome: Systemic review of observational studies and historical review of recommendations from 1940 to 2002. Int J Epidemil. 2005; 34: 874-887.

82. Jeffrey HE, Megevand A, Page M. Why the prone position is a risk factor for sudden infant death syndrome. Pediatrics. 1999; 104: 263-269. 
83. Leiter JC, Bohm I. Mechanisms of pathogenesis in the sudden infant death syndrome. Resp Physiol Neurobiol. 2007; 159: 127-138.

84. Ulualp SO, Toohill RJ, Kern M, Shaker R. Pharyngo-UES contractile reflex in patients with posterior laryngitis. Laryngoscope. 1998; 108: 1354-1357.

85. Trifan A, Shaker R, Ren J, Mittal RK., Saeian K, Dua K, Kusano M. Inhibition of resting lower esophageal sphincter pressure by pharyngeal water stimulation in humans. Gastroenterology. 1995; 108: 441-446.

86. Mittal RK, Chiareli C, Liu J, Shaker RE. Characteristics of lower esophageal sphincter relaxation induced by pharyngeal stimulation with minute amounts of water. Gastroenterology. 1996; 111: 378-384.

87. Trifan A, Ren J, Arndorfer R, Hofmann C, Bardan E, Shaker RE. Inhibition of progressing primary esophageal peristalsis by pharyngeal water stimulation in humans. Gastroenterology. 1996; 110: 419-423.

88. Bardan E, Xie P, Ren J, Dua K, Shaker RE. Effects of pharyngeal water stimulation on esophageal peristalsis and bolus transport. Am J Physiol-Gastr L. 1997; 272: 265-271.

89. Bardan E, Saeian K, Xie P, Ren J, Kern M, Dua K, et al. Effect of pharyngeal stimulation on the motor function of the esophagus and its sphincters. Laryngoscope. 1999; 109: 437-441.

90. Bardan E, Xie P, Aslam M, Kern M, Shaker R. Disruption of primary and secondary esophageal peristalsis by afferent stimulation. Am J Physiol-Gastr L. 2000; 279: 255-261.

91. Lang IM, Medda BK, Xie P, Ren J, Shaker RE. Mechanism of pharyngoesophageal inhibitory reflex in the cat. Am J Physiol-Gastr L. 1998; 275: 1127-1136.

92. Shaker RE, Ren J, Kern M, Dodds WJ, Hogan WJ, Li Q. Mechanism of airway protection and upper esophageal sphincter opening during belching. Am J Physiol-Gastr L. 1992; 262: 621-628.

93. Shaker RE, Dodds WJ, Ren J, Hogan WJ. Esophagoglottal closure reflex: A mechanism of airway protection. Gastroenterology. 1992; 102: 857-861.

94. Shaker R, Ren J, Medda BK, Lang IM, Cowles V, Jaradeh S. Identification and characterization of the esophago-glottal closure reflex in a feline model. Am J Physiol-Gastr L. 1994; 266: 147153.

95. Lang IM, Haworth ST, Medda BK, Roerig DL, Forster HV, Shaker RE. Airway responses to esophageal acidification. Am J Physiol-Gastr L. 2008; 294: 211-219.

96. Lang IM, Haworth ST, Medda BK, Forster HV, Shaker RE. Mechanisms of airway responses to esophageal acidification in cats. Am J Physiol-Gastr L. 2016; 120: 774-783.

97. Mazzone SB, McGovern AE. Innervation of tracheal parasympathetic ganglia by esophageal cholinergic neuron: Evidence from anatomic and functional studies in guinea pigs. Am J Physiol Lung Cell Mol Physiol. 2010; 298: 404-416.

98. Wine JJ. Parasympathetic control of airway submucosal glands: Central reflexes and airway intrinsic nervous control. Auton Neurosci. 2007: 133: 35-54.

99. Sonntag SJ, Harding SM. Gastroesophageal reflux and asthma. GI Motility Online. 2006. Available From: https://www.nature.com/gimo/contents/pt1/full/gimo47.html.

100. Mittal RK. Longitudinal muscle of the esophagus: Its role in esophageal health and disease. Curr Opinion Gastroenterol. 2013; 29: 421-430.

101. Mittal RK. Motor and sensory function of the esophagus: Revelations through ultrasound imaging. J Clin Gastroenerol. 2005; 39: 42-48. 
102.Abrahao L, Bhargava V, Babaei A, Ho A, Mittal RK. Swallow induces a peristaltic wave of distension that marches in front of the peristaltic wave of contraction. Neurogastroenterol Motil. 2011; 23: 201-210.

103.Liu J, Puckett JL, Takeda T, Jung HY, Mittal RK. Crural diaphragm inhibition during esophageal distension correlates with contraction of the esophageal longitudinal muscle in cats. Am J Physiol-Gastr L. 2005; 288: 927-932.

104.Jiang Y, Bhargava V, Mittal RK. Mechanisms of stretch-activated excitatory and inhibitory responses in the lower esophageal sphincter. Am J Physiol-Gastr L. 2009; 297: 397-405.

105.Altschuler SM, Boyle JT, Nixon TE, Pack Al, Cohen S. Simultaneous reflex inhibition of lower esophageal sphincter and crural diaphragm. Am J Physiol-Gastr L. 1985; 249: 586-591.

106.Lesle E, Bhargava V, Mittal RK. A novel pattern of longitudinal muscle contraction with subthreshold pharyngeal stimulus: A possible mechanisms of lower esophageal sphincter relaxation. Am J Physiol-Gastr L. 2012; 302: 542-547.

107.Trifan A, Shaker R, Ren J, Mittal RK, Saeian K, Dua K, et al. Inhibition of resting lower esophageal sphincter pressure by pharyngeal water stimulation in humans. Gastroenterology. 1995; 108: 441-446.

108. Mittal RK, Ciareli C, Liu J, Shaker RE. Characteristics of lower esophageal sphincter relaxation induced by pharyngeal stimulation with minute amounts of water. Gastroenterology. 1996; 111: 378-384.

109. Mittal RK. The crural diaphragm, an external lower esophageal sphincter: A definitive study. Gastroenterology. 1993; 105: 1565-1567.

110.Dong H, Jiang Y, Dong J, Mittal RK. Inhibitory motor neurons of the esophageal myenteric plexus are mechanosensitive. Am J Physiol-Gastr L. 2105; 308: 405-413.

111.Franzl SJ, Martin CJ, Coox MR, Dent J. Response of canine lower esophageal sphincter to gastric distension. Am J Physiol-Gastr L. 1990; 259: 380-385.

112. Mittal RK, Holloway RH, Penagini R, Blackshaw LA, Dent J. Transient lower esophageal sphincter relaxation. Gastroenterology. 1995; 109: 601-610.

113.Ayazi S, Tamhankar A, DeMeester SR, Zehetnber J, Wu C, Lipham JC, et al. The impact of gastric distension on the lower esophageal sphincter and its exposure to acid gastric juice. Ann Surgery. 2010; 252: 57-62.

114. Martin CJ, Dodds WJ, Liem HH, Dantas RO, Layman RD, Dent J. Diaphragmatic contribution to gastroesophageal competence and reflux in dogs. Am J Physiol. 1992; 263: 551-557.

115.Lang IM, Medda BK, Shaker RE. Mechanism of UES relaxation initiated by gastric air distension. Am J Physiol-Gastr L. 2014; 307: 452-458.

116.Penagini R, Carmagnola S, Cantu P, Alloca M, Bianchi PA. Mechanoreceptors of the proximal stomach: Role in triggering transient lower esophageal sphincter relaxation. Gastroenterology. 2004; 126: 49-56.

117. Martin CJ, Patrikios J, Dent J. Abolition of gas reflux and transient lower esophageal sphincter relaxation by vagal blockade in the dog. Gastroenterology. 1986; 91: 890-896.

118.Dodds WJ, Dent J, Hogan WJ, Helm JF, Hauser R, Patel GK. Mechanism of gastroesophageal reflux in patients with reflux esophagitis. N Engl J Med. 1982; 307: 1547-1552.

119. Holloway RH, Hongo M, Berger K, McCallum RW. Gastric distension: A mechanism for postprandial gastroesophageal reflux. Gastroenterology. 1985; 89: 779-784. 


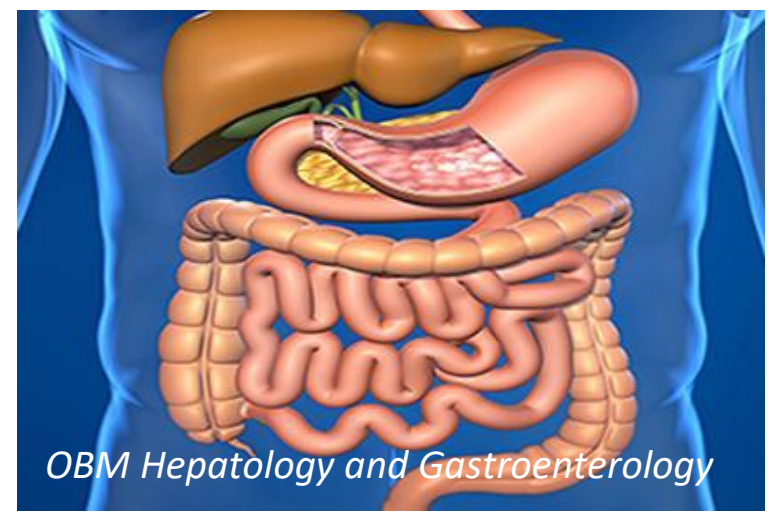

Enjoy OBM Hepatology and Gastroenterology by:

1. Submitting a manuscript

2. Joining in volunteer reviewer bank

3. Joining Editorial Board

4. Guest editing a special issue

For more details, please visit:

http://www.lidsen.com/journals/hg 